\title{
GPCR-Based Dopamine Sensors-A Detailed Guide to Inform Sensor Choice for In Vivo Imaging
}

\author{
Marie A. Labouesse ${ }^{1,2,+}$, Reto B. Cola ${ }^{3,4,+}$ and Tommaso Patriarchi ${ }^{4,5, * \text { (D) }}$ \\ 1 Department of Psychiatry, College of Physicians and Surgeons, Columbia University, New York, NY 10032, \\ USA; mal2307@cumc.columbia.edu \\ 2 Division of Molecular Therapeutics, New York State Psychiatric Institute, New York, NY 10032, USA \\ 3 Anatomy and Program in Neuroscience, University of Fribourg, 1700 Fribourg, Switzerland; \\ reto.cola@uzh.ch \\ 4 Institute of Pharmacology and Toxicology, University of Zurich, 8057 Zurich, Switzerland \\ 5 Neuroscience Center Zurich, University and ETH Zurich, 8057 Zurich, Switzerland \\ * Correspondence: patriarchi@pharma.uzh.ch; Tel.: +41-044-635-59-21 \\ + These authors share equal co-first contribution.
}

Received: 10 September 2020; Accepted: 26 September 2020; Published: 28 October 2020

check for updates

\begin{abstract}
Understanding how dopamine (DA) encodes behavior depends on technologies that can reliably monitor DA release in freely-behaving animals. Recently, red and green genetically encoded sensors for DA (dLight, GRAB-DA) were developed and now provide the ability to track release dynamics at a subsecond resolution, with submicromolar affinity and high molecular specificity. Combined with rapid developments in in vivo imaging, these sensors have the potential to transform the field of DA sensing and DA-based drug discovery. When implementing these tools in the laboratory, it is important to consider there is not a 'one-size-fits-all' sensor. Sensor properties, most importantly their affinity and dynamic range, must be carefully chosen to match local DA levels. Molecular specificity, sensor kinetics, spectral properties, brightness, sensor scaffold and pharmacology can further influence sensor choice depending on the experimental question. In this review, we use DA as an example; we briefly summarize old and new techniques to monitor DA release, including DA biosensors. We then outline a map of DA heterogeneity across the brain and provide a guide for optimal sensor choice and implementation based on local DA levels and other experimental parameters. Altogether this review should act as a tool to guide DA sensor choice for end-users.
\end{abstract}

Keywords: behavior; drug screening; genetically encoded; dopamine; fiber photometry; fluorescent biosensor; in vivo fluorescent imaging; neuromodulator; pharmacology

\section{Introduction}

\subsection{Measuring Neuromodulator Release During Behavior}

Animals must constantly adjust their behavior to meet the demands of ever-changing sensory inputs, external environments and internal needs. Neuromodulators, such as dopamine (DA), provide one evolutionary conserved mechanism that supports this behavioral adaptability. By rapidly modifying the properties of their target neurons, neuromodulators can deeply affect neural circuits and in turn modulate behavior [1-4]. Disturbances in neuromodulatory signaling pathways are associated with a large number of behavioral dysfunctions and brain pathologies including psychotic and mood disorders, motor diseases or addiction. A key challenge for neuroscientists is the ability to understand how neuromodulators encode and control behavioral outputs in health and disease states and in turn 
how these neuromodulators can be harnessed to treat brain disorders. The ability to answer these questions is dependent on available technologies that can reliably monitor neuromodulatory processes, including (i) action potential (AP) propagation and (ii) synaptic release. Advanced in vivo imaging methods to track AP propagation in genetically defined cells have been developed across the past decades, most notably in vivo calcium imaging, the method of choice for monitoring intracellular calcium levels as a proxy for AP propagation [5]. Calcium imaging relies on the usage of high resolution genetically encoded calcium indicators (GECIs) (e.g., GCaMP), which detect calcium-dependent changes in the chromophore environment of ultrasensitive circularly permuted fluorescent proteins (cpFP) (e.g., the green cpGFP) [6-9].

However, neuromodulator release does not linearly correlate with AP propagation but instead can undergo local regulation in an AP-independent manner, for example via presynaptic autoreceptor mechanisms [10,11]. Once released, neuromodulators act onto their cognate receptors expressed on the membranes of receiving cells. Receptor activation modulates downstream signaling cascades which in turn can dramatically impact vesicular release probability, firing patterns, excitability or plasticity within the local microcircuit [2-4,12]. Because neuromodulator kinetics are selectively regulated by release and reuptake mechanisms, the time they spend in the extracellular space directly relates to their downstream actions [13]. Thus, the ability to measure extracellular levels of neuromodulators with high spatiotemporal resolution during behavior becomes essential to gain deeper insights into how neuromodulator release encodes behavior.

\subsection{Heterogeneity of Brain Dopamine Systems}

Dopamine is one of several neuromodulators broadly expressed throughout the brain [14]. The DA system is best known for its roles in reward behavior [15-18], action learning [19] and motor function [20] but its effects extend to many other functional domains. For instance, DA has been extensively shown to regulate cognitive function [21,22], aversive processing [17,23], social interaction [24], feeding behavior [25-28], physical activity [29-31] or metabolic and hormonal homeostasis [32-34]. These many functions are modulated by a broad network of DA projection neurons, arising from nine major DAergic cell groups labeled A8 to A16 [35], as originally introduced by Dahlström and Fuxe in 1964 [36]. Thus, while DA release from ventral midbrain neurons into the dorsal striatum and nucleus accumbens (NAc) are by far the most studied [14], DA is also released in a sparser fashion by neurons with cell bodies in the hypothalamus [37], dorsal raphe [24,38] or locus coeruleus [39,40], to name a few. Moreover, responses to DA can be found in many DA-recipient regions including the medial prefrontal cortex (mPFC) [22,23], hippocampus [24], midbrain [41], paraventricular thalamus (PVT) [39], amygdala [24], septum [42] or ventral pallidum [43] and globus pallidus (GPe) [44]. Importantly, there is a large regional heterogeneity in DA innervation patterns and DA concentrations across brain regions. While the dorsal striatum and NAc are heavily innervated by dense DA projections arising from the midbrain, other brain regions receive much sparser projections $[35,45,46]$. Moreover, basal and evoked DA levels measured by analytical methods can also vary by a factor of at least 10 in more sparsely innervated regions as compared to the striatum [47]. For example, Koch et al., (2002) reported basal DA levels of $5.8 \pm 0.7 \mathrm{nM}$ in the dorsal striatum, $4.5 \pm 1.6 \mathrm{nM}$ in the NAc, $0.26 \pm 0.05 \mathrm{nM}$ in the hypothalamus and $0.30 \pm 0.1 \mathrm{nM}$ in the $\mathrm{mPFC}$ in awake rats using microdialysis [48], showing the large variability across brain regions.

\subsection{Measuring Dopamine Across Brain Regions}

Thus, a key challenge for systems and behavioral neuroscientists is the ability to measure DA across densely and sparsely innervated regions and to correlate in vivo DA levels with relevant behavioral outputs. The ability to answer these questions is dependent on available technologies that can reliably monitor DAergic processes in the slice or the awake behaving animal, even when DA concentrations are low. Historically, in vivo measurements for DA have been tackled with classical analytical chemistry techniques, such as microdialysis or fast-scan cyclic voltammetry (FSCV). These methods 
have transformed our ability to measure neuromodulators in vivo in the past five decades but face limitations that prevent long-term measurements at adequate spatiotemporal resolution and/or specificity, in particular in regions with relative sparse DA innervation. In the past few years, however, scientists have developed a large palette of genetically encoded sensors that surpass some of these technical barriers. This initially included cell-based sensors that are based on dual wavelength FRET imaging (CNiFERs) [49] and other probes that track DA receptor-dependent changes in gene expression (iTango2 and SPARK) [50,51]. Genetically encoded calcium sensors, in particular those targeted to the axon or synapse (axon-GCAMP, synaptophysin-GCAMP) [52,53] also provide indirect measures of DA release by virtue of measuring axonal and/or presynaptic calcium transients in DA neurons and can track activity even if the local DA release levels are low $[23,54,55]$. Technologies that track DA release in brain slices have also been developed in recent years, most notably in the form of false fluorescent neurotransmitters (FFNs) [56] and carbon nanotubes [57]. Although they are more difficult to apply in vivo, they provide useful ex vivo platforms to study DA dynamics with high spatiotemporal resolution and sensitivity.

More recently, we and others developed red and green genetically encoded DA biosensors based on cpFPs (previously used for calcium sensors) engineered into a DA receptor, which now allow us to track fluorescent changes at a subsecond resolution, with submicromolar affinity and high molecular specificity. These include our 8 red, yellow and green RdLight1/YdLight1/dLight1sensors [58,59], as well as the 6 GRAB-DA sensors, all harboring their own specific properties $[60,61]$. Combined with rapid developments in in vivo imaging techniques [62], such as multiplexed fiber photometry [63-65], head-mounted microendoscopes [66,67] and 2-photon endoscopy and mesoscopy [68,69], these sensors have the potential to transform the field of DA sensing as they allow us to monitor DA dynamics in vivo with unprecedented spatiotemporal resolution (see Figure 1 for examples of applications).

\subsection{Sensor Choice Depends on Brain Region Dopamine Levels and Other Experimental Modalities}

When implementing these tools in a new brain region, it is important to keep in mind that often there is not a 'one-size-fits-all' sensor. Sensor properties, most importantly their ligand-binding affinity must be carefully chosen to match local levels of DA in the brain region of interest (ROI). Moreover, experimental paradigms largely differ from each other where, for each given question, specific sensor properties take priority. For instance, fast sensor kinetics are most crucial in behavioral experiments harboring highly frequent stimuli and events but sensor molecular specificity will matter most when attempting to distinguish the dual dynamics of two neuromodulators (e.g., DA/noradrenaline, NE). Sensor spectrum will be important in multiplex experiments and sensor brightness will be key in 1 and 2-photon imaging. Importantly, G-protein coupled receptor (GPCR) sensors inherit the pharmacological properties of their parent DA receptor [58,59], making sensor fluorescence a putative readout for receptor subtype activation: this feature may be incompatible with certain pharmacological applications but can also be harnessed as a tool to screen candidate drugs based on their ability to engage certain receptor subtypes.

In this review, we start by briefly reviewing the broad number of techniques to monitor DA release (for further review see Reference [70]), including the recently developed genetically encoded DA sensors. We then outline a detailed map of DA innervation patterns as well as basal and evoked DA levels across the brain. We use this map to illustrate how end-users can optimize sensor choice according to their brain ROI. We also provide a guide for sensor choice based on other experimental parameters. We primarily focus on in vivo imaging conditions in rodents but this review can also inform research in other animal models or in vitro assays. Moreover, these guidelines are likely to be relevant for other existing neuromodulator sensors such as NE, acetylcholine, serotonin or adenosine sensors [71-76]. 




Figure 1. In vivo applications of dLight1 and RdLight1 dopamine (DA) sensors in mice. Graphs show normalized fluorescent responses (dFF). (a) dLight1 variants were validated in multiple imaging and experimental modalities: (i) dual-color fiber photometry of nucleus accumbens (NAc) cells using the red-shifted calcium sensor jRGECO1a [77] and local DA release using dLight1.1 following unpredictable shock exposure (dotted line); (ii) fiber photometry imaging of DA release using dLight1.1 in the NAc following optogenetic stimulation (5-20 Hz, 2 seconds) of DA cell bodies in the ventral tegmental area (VTA) using the red-shifted opsin ChrimsonR; (iii) two-photon imaging of DA release (dLight1.2) (top) across heterogeneous sites in motor cortex (M1/M2) across $17 \mu \mathrm{M}$ large regions of interest (= red square ROIs, bottom), here showing ROIs responsive to locomotion/reward expectation vs. rest (green vs. orange) at the Go cue (vertical line) and increases in fluorescence upon reward delivery (dark green) but not reward omission (light green) (population data) (middle). (b) RdLight1 validations: (i) dual-color fiber photometry of VTA terminals in the NAc using the green axon-targeted calcium sensor axon-GCaMP6f [52] and local DA release using RdLight1 following unexpected, audible reward deliveries (dotted line) and (ii) fiber photometry imaging of DA release using RdLight1 in the NAc following optogenetic stimulation (1-32 pulses; 2 seconds) of DA cell bodies in the VTA using the green opsin ChR2. 


\section{Currently Available Methods to Measure Dopamine Release}

\subsection{Analytical Chemistry: Microdialysis (In Vivo) and FSCV (Ex Vivo and In Vivo)}

Analytical chemistry techniques such as microdialysis, FSCV and amperometry have provided critical tools to measure brain levels of DA ex vivo and in vivo across the past five decades [78]. These methods have transformed our understanding of DA function and their relations to behavior. Microdialysis is an in vivo technique based on dialysate sampling of cerebrospinal fluid through a semi-permeable membrane-containing probe implanted into the brain tissue of a living animal. Samples are analyzed by analytical techniques such as high-performance liquid chromatography (HPLC). Microdialysis has excellent sensitivity (nanomolar) and molecular specificity and can therefore discriminate amongst a plethora of different neuromodulators including DA, NE, serotonin, acetylcholine and others. Thus, microdialysis remains an essential quantitative tool to evaluate the basal concentration of multiple neurotransmitters simultaneously in identified brain regions. However, due to constraints on dialysate dilution, neurotransmitter diffusion kinetics and slow collection times, the temporal resolution of microdialysis is slow: on the scale of minutes (five minutes on average). The spatial resolution is also low, for example, $\sim 0.5 \mathrm{~mm}$ for a $200 \mu \mathrm{m}$ diameter microprobe $[79,80]$. As a consequence, microdialysis is limited in its ability to track phasic changes in DA release or transients of small magnitude in regions of sparse innervation as these fast or small changes are diluted within the dialysate over time. Thus, although microdialysis has been successfully used in regions with sparse DA like the mPFC to track basal and evoked DA, they do not succeed in capturing the full temporal dynamics of release due to these limitations. For instance, low levels of DA near detection threshold could be reported in the GPe in vivo but this was only achieved by accruing the dialysate over tens of minutes, thus losing crucial temporal information [81].

Electrochemical methods such as FSCV use a carbon-fiber probe inserted into the brain (in vivo) or onto a slice (ex vivo) to detect voltage-dependent oxidation/reduction profiles characteristic of specific neurotransmitters [82]. FSCV offers excellent sensitivity (nanomolar) and high temporal resolution (subsecond range). The thin $(7 \mu \mathrm{m})$ implanted carbon fiber electrodes cause minimal intracerebral damage, offers superior spatial resolution $(<10 \mu \mathrm{m})$ vs. microdialysis [82] and in principle microarrays can be used to record multiple channels at once $[83,84]$. FSCV thus remains an essential tool to estimate the evoked concentration of DA in identified brain regions in a quantitative manner, including in brain regions with sparse DA innervation. FSCV does, however, rely on background subtraction and lacks the molecular specificity necessary to discriminate neuromodulatory molecules from their metabolites which have similar electrochemical properties [82]. For instance, FSCV does not distinguish DA from $\mathrm{NE}$, an important limitation for brain regions with dual innervation like the mPFC [85]. However, FSCV is not affected by the presence of DA receptor ligands (as is the case for dLight and GRAB-DA, see Section 5.6), making FSCV a useful method to deploy in combination with drug treatments and/or in drug addiction research.

Finally, it is worth noting that analytical chemistry methods are also not genetically encoded and therefore lack the cellular resolution required for many applications.

\subsection{False Fluorescent Neurotransmitters (Ex Vivo)}

False fluorescent neurotransmitters (FFNs) represent another highly relevant technique to monitor DA release, primarily in brain slices. FFNs are hydrophilic fluorescent probes that mimic the topology and properties of the neurotransmitter of interest and can therefore be taken up into synaptic vesicles and discharged during exocytosis; thus tracking FFN staining and destaining in the vesicle provides an indirect measure of synaptic release dynamics. For instance, FFN200 is a substrate for the vesicular monoamine transporter, VMAT2, that has been specifically engineered to track DA or NE release in slices. One main advantage of FFNs, in particular FFN200, is the ability to track synaptic vesicle fusion and exocytosis from individual single-site synaptic release sites on the axon, thus granting exceptional spatial resolution $[56,86]$. Moreover, $\mathrm{pH}$-sensitive FFNs such as FFN102 were also developed to 
increase FFN signal to noise ratio (SNR) by harnessing the existing $\mathrm{pH}$ gradient that differentiates acidic synaptic vesicles from the extracellular space. Thus FFN102 is particularly useful to track DA release in brain regions with sparse innervation such as demonstrated in the GPe in Reference [44]. It is important to note, however, that FFN imaging of DA release has hitherto not been applied successfully in vivo due to the difficulty of the in vivo loading process. In vivo imaging of FFN270 for NE has recently been performed using 2-photon imaging through a cranial window, indicating the potential of these techniques to extend to the in vivo preparation [87]. Other limitations for in vivo experiments include the lack of molecular specificity of FFNs for DA over NE and the relatively low temporal resolution (several seconds).

\subsection{Carbon Nanotubes (Ex Vivo)}

Another method to track DA release ex vivo includes single-walled carbon nanotubes (SWCNT) [88]. Carbon nanotubes are cylindrical molecules that consist of rolled-up sheets of single-layer carbon atoms with diameters typically in the range of nanometers. To develop an optical probe for catecholamines, including DA, near-infrared intrinsically fluorescent SWCNTs were pinned with catecholamine-sensitive functional polymers such that the fluorescent signal increases upon binding with catecholamines (DA or NE) $[57,88]$. When applied to brain slices, newly developed catecholamine SWCNTs (nIRCat) offered excellent temporal resolution (subsecond), comparable to that of FSCV or DA biosensors. Moreover, preliminary results indicated that nIRCat can detect heterogeneity of DA release sites with a spatial resolution in the single-digit micrometer range $(4 \mu \mathrm{M}$ ROIs) even in brain slices [57]. Prior work in cells also showed that a different version of catecholamine SWCNTs could be positioned into nanoarrays, allowing to dissect the spatial spread of DA transmission with unsurpassed spatiotemporal resolution $(<1 \mu \mathrm{M}$ ROIs) along the membrane of single neurons in culture [89] (see also [90] for a detailed review). These nanoarray methods can hopefully be applied to brain slices in the future, possibly even by tailoring their location to for example postsynaptic sites using recognition motifs [90]. Unlike DA biosensors, catecholamine SWCNTs are resistant to photobleaching. They also remain insensitive to DA ligands and are thus more easily combined with DA drug manipulations or drug addiction investigations [57]. Due to their near infrared fluorescent profile, catecholamine SWCNTs are potentially compatible with mesoscopic through-cranium imaging or multiphoton imaging due to low light absorption and scattering and low autofluorescence [90]; although this needs to be determined in future studies. One hurdle is the lack of molecular specificity, as catecholamine SWCNTs are sensitive to both DA and NE [57], which remains problematic in brain regions with dual DA/NE innervation like the mPFC. Moreover, as catecholamine SWCNTs are not genetically encoded and need to be loaded by diffusion [57], it remains to be determined whether they can reliably be deployed into an in vivo preparation.

\subsection{GPCR FRET-Based Sensors: CNiFERs (Ex Vivo and In Vivo)}

Another recent addition to the toolbox to measure DA release in vivo is based on the expression of GPCRs coupled to Gq in clonal cell lines such as HEK293 cells (CNiFERs: cell-based neurotransmitter fluorescent engineered reporters) $[49,91]$. Upon activation of these GPCRs, the Gq pathway activates phospholipase $\mathrm{C}$ and hence results in IP3-mediated release of intracellular calcium from the endoplasmic reticulum. This increase in intracellular calcium is detected by a FRET-based calcium-sensor co-expressed by the clonal cell line. This approach has been successfully used to sense DA and $\mathrm{NE}$ in vivo at nanomolar concentrations with reasonable spatial resolution $(100 \mu \mathrm{M})$ [91]. This was achieved with high molecular specificity given that CNiFERs inherit the molecular specificity of the GPCR they express. One limitation, however, is the low temporal resolution (5 seconds) due to the dependence on $\mathrm{Gq}$ downstream signaling. Moreover, the invasive nature of the cell implantation and associated mild inflammation, hinders experiments longer than 1 week post injection [49]. However, due to their higher resistance to photobleaching, CNiFERs can be particularly useful to track DA changes across broad time periods for example, hours-long sessions or across days. 


\subsection{GPCR Signal Transduction Sensors: iTango2 and SPARK (Ex Vivo and In Vivo)}

Another GPCR-based system developed recently, iTango2, is an inducible genetically encoded system that was designed to capture signaling cascades downstream of GPCR activation, in particular the DA D2 receptor (DRD2). The Tango system was originally developed by fusing the transcription factor tTA to the $C$-terminal domain of the GPCR of interest (e.g., DRD2) via a peptide sequence (TEV) containing a protease cleavage site [92,93]. Upon DA binding to the receptor and GPCR-activation of the beta-arrestin downstream pathway, the TEV is recruited to the receptor, the TEV sequence cleaved, releasing the transcription factor tTA which can in turn activate transcription of a reporter gene (e.g., a fluorescent protein) via interaction with a tetracycline response element (TRE). This system allowed nanomolar sensitivity detection of DA in a restricted brain region, albeit with low temporal resolution (hours) but with, in principle, a spatial resolution of single cells. However, in the improved version iTango2 [51], as well as in SPARK [50], the protease cleavage is further dependent on the presence of blue light, making it possible to optogenetically activate the system on demand ex vivo or in vivo, leading to spatial restriction as well as higher temporal resolution (minutes). One important limitation for these methods in vivo is that they can only report neuromodulator signaling at a single timepoint and thus cannot be used for real time monitoring of DA release. They do, however, represent important tools to track activation of DRD2 over minutes, hours or even days (as the gene expression changes can last several days). Importantly, iTango2 does not only allow to track but also to manipulate cells involved in a task, by expressing genes under the control of TRE following iTango2 labeling. Thus, iTango2 allows to test the causal role of specific cell types activated by DA during behavior.

\subsection{Genetically Encoded Calcium Sensors (Ex Vivo and In Vivo)}

Another method to access DA dynamics is to make use of calcium sensors (GCaMPs) to monitor neural dynamics of DA axons as a proxy for release. Indeed, GCaMPs are widely used to track calcium dynamics in neurons as a proxy for neural activity with the advantage of high spatiotemporal resolution (up to individual dendrites/axons) and cell specificity $[7,8]$. GCaMPs detect calcium-dependent changes in the chromophore environment of their ultrasensitive cpGFP [6-9]. Classically, GCaMP expression is enriched in somatodendritic compartments including dendritic spines where they primarily track post-synaptic calcium transients evoked by afferent activity [6]. However, more recent versions of GCaMPs such as GCaMP7 [8] (and to a lesser extent: GCaMP6 [7]) are more broadly expressed in thin subcellular compartments such as axons and thus reliably track axonal and presynaptic calcium transients along the branches induced by action potentials [8]. These sensors can therefore be used to detect activity of long-range DA axons given that the somatodendritic transients (e.g., in the midbrain) detected by GCaMP will not interfere with axonal signals (e.g., in the striatum) as they are physically removed from each other. They have the added advantage of tracking neural activity in brain regions even if the local DA release levels are low. Thus, GCaMPs represent a useful proxy to estimate DA release dynamics; for example, GCAMP6f imaging has been successfully performed in the striatum to evaluate the dynamics of arising midbrain DA signals during locomotion and reward tasks $[54,55,94]$.

Moreover, new versions of GCaMP using targeting motifs to enhance expression to the axon (axon-GCaMP6) [52] or the presynapse (Synaptophysin-GCAMP6) [53] were recently developed and thus represent even more precise methods to track axonal/presynaptic activity as a proxy for DA release. For example, we identified high fidelity between axonal calcium levels arising from the midbrain (measured with axon-GCaMP6f) and DA release (measured with RdLight1) in the NAc in a reward task [59]. Of note, Synaptophysin-GCaMP6 has limited photostability and thus should be reserved for experiments of short duration ( $\mathrm{a}$ few hundreds of seconds) [52]. These tools can be particularly useful in brain regions with sparse neuromodulator innervation where DA sensors may still lack sensitivity (as outlined more in detail below).

It is important to note, however, that DA release may occur independent of calcium dynamics as it is regulated locally by multiple presynaptic mechanisms including D2 autoreceptors or cholinergic innervation (for reviews on DA release see: $[11,18,95,96]$ ), making DA biosensors particularly important 
in this context. Moreover, several studies have found that somatodendritic DA release in the midbrain is less dependent on calcium as compared to axonal release in the striatum, making GCaMPs a less appropriate tool to study such somatodendritic release mechanisms. Nonetheless, combined monitoring of calcium transients (GCaMPs) and DA release (dLight/GRAB-DA) can represent a powerful platform to understand how neural activity shapes release dynamics, as demonstrated in recent preprints for acetylcholine [97] or DA [98].

\section{Catalogue of GPCR Biosensors for Dopamine}

\subsection{The GPCR Dopamine Sensor Toolbox (Ex Vivo and In Vivo)}

Single-wavelength GPCR biosensors for DA represent the latest method to track DA release ex vivo and in vivo with high spatiotemporal resolution and molecular specificity [99]. For simplicity we now refer to these as DA biosensors. Since GPCRs are native target receptors for many neuromodulators, including DA, we and others recently established an approach to design sensors based on protein engineering of the cognate receptors $[58,60,71-73]$. Sensors were based on the insertion of a green (cpGFP) or red (cpmApple) module (the same ones previously used for GCaMPs or jRGECO1a [6-8,77]) into the third intracellular loop of one of the five receptors (= GPCR) for DA (DRD1-DRD5), thus allowing to transform receptor activation into a fluorescent readout. Upon binding of the endogenous ligand (DA or other neuromodulator), the GPCR undergoes a large conformational change leading to an increase in the fluorescent intensity of the cpGFP/cpmApple due to changes in its chromophore environment [6]. Biosensors for DA (dLight1, RdLight1, GRAB-DA1) [58-60,100], as well as for other neuromodulators (NE, acetylcholine, adenosine) [71-74,76] have already been established, while more advanced versions of DA sensors (GRAB-DA2, GRAB-rDA1) [61] and other sensors (serotonin) [75] are in development.

In Table 1 you will find a summary of currently available DA biosensors as well as their main properties, which are further detailed in Section 5. DA biosensors have already generated key findings in the basic understanding of reward behavior [101-107], thirst regulation [108], feeding behavior [109], addiction [38,110,111], aversive learning [112], depressive-like behavior [98], sleep-wake cycle [113] or to dissect neuromodulator mechanisms in disease models [114,115] using a variety of in vivo imaging modalities shown in Figure 1. DA biosensors can also be used to understand DA release dynamics in vitro or ex vivo [58-61], as shown for example in Reference [116] where dLight1 was used to understand the metabolic demands and bioenergetic roles of the mitochondria in governing phasic DA release.

\subsection{Advantages of GPCR Dopamine Biosensors}

What are some reasons for the in vivo performance of DA biosensors compared to other available methods?

First, DA biosensors demonstrated excellent fluorescent sensitivity and brightness in response to ligand binding, making them ideally suited for in vivo imaging. This is because sensors were generated using a cpGFP/cpmApple module that had already been optimized for calcium sensors through iterative processes $[6-8,77]$. This led to the creation of first-generation single-wavelength sensors that already harbor large fluorescence changes during GPCR activation and decent brightness. First- and second-generation GPCR DA biosensors thus demonstrated a peak increase in fluorescence (dFF) of at least $90 \%$ and up to $900 \%$ in response to ligand binding (see Table 1) (e.g., $340 \%$ for both dLight1.2 and GRAB-DA2m), compared to 5\% for FRET sensors [117]. These properties have made DA biosensors easy to implement in the laboratory. 
Table 1. The G protein coupled receptors (GPCR) dopamine biosensor toolbox and intrinsic properties.

\begin{tabular}{|c|c|c|c|c|c|c|c|c|}
\hline Sensor & $\begin{array}{l}\text { Molecular } \\
\text { Scaffold }\end{array}$ & $\begin{array}{c}\text { Affinity } \\
\left(K_{d} / E_{50}\right)\end{array}$ & $\begin{array}{c}\text { Dynamic } \\
\text { Range }\left(\mathrm{dFF}_{\max }\right)\end{array}$ & $\begin{array}{l}\text { Molecular } \\
\text { Specificity } \\
\text { vs. NE }\end{array}$ & $\begin{array}{l}\text { On Kinetics: } \\
\mathbf{t}_{1 / 2} \text { Rise Time }\end{array}$ & $\begin{array}{c}\text { Off Kinetics: } \\
\mathbf{t}_{1 / 2} \text { Decay Time }\end{array}$ & $\begin{array}{l}\text { 1-Photon } \\
\text { Exc/Emis }\end{array}$ & Source \\
\hline dLight1.1 & DRD1 & $330 \mathrm{nM}^{*}$ & $230 \% *$ & 70-fold & $10 \mathrm{~ms}^{* *}$ & $100 \mathrm{~ms}^{* *}$ & $490 / 517 \mathrm{~nm}$ & [58] \\
\hline dLight1.2 & DRD1 & $765 \mathrm{nM}^{*}$ & $340 \%$ * & ND & $9.5 \mathrm{~ms}^{* *}$ & $90 \mathrm{~ms}^{* *}$ & $490 / 517 \mathrm{~nm}$ & [58] \\
\hline dLight1.3a & DRD1 & $2300 \mathrm{nM}^{*}$ & $660 \% *$ & ND & ND & ND & ND & [58] \\
\hline dLight1.3b & DRD1 & $1600 \mathrm{nM}^{*}$ & $930 \% *$ & 270-fold & ND & ND & ND & {$[58,101]$} \\
\hline dLight1.4 & DRD4 & $4 \mathrm{nM}^{*}$ & $170 \%$ * & ND & ND & ND & ND & [58] \\
\hline dLight1.5 & DRD2 & $110 \mathrm{nM}^{*}$ & $180 \%$ * & ND & ND & ND & ND & [58] \\
\hline RdLight1 (red) & DRD1 & $860 \mathrm{nM}^{*}$ & $250 \%$ * & 60-fold & $14 \mathrm{~ms}^{* *}$ & $400 \mathrm{~ms}^{* *}$ & $560 / 588 \mathrm{~nm}$ & [59] \\
\hline YdLight1 (yellow) & DRD1 & $1630 \mathrm{nM}^{*}$ & $310 \%$ * & ND & ND & ND & $514 / 525 \mathrm{~nm}$ & [59] \\
\hline GRAB-DA1m & DRD2 & $130 \mathrm{nM} *$ & $90 \%$ * & 10-fold & $60 \mathrm{~ms}^{*}$ & $710 \mathrm{~ms}^{*}$ & $490 / 510 \mathrm{~nm}$ & [60] \\
\hline GRAB-DA1h & DRD2 & $10 \mathrm{nM}^{*}$ & $90 \% *$ & 10-fold & $140 \mathrm{~ms}^{*}$ & $2520 \mathrm{~ms}^{*}$ & $490 / 510 \mathrm{~nm}$ & [60] \\
\hline GRAB-DA2m & DRD2 & $90 \mathrm{nM}^{*}$ & $340 \%$ * & 22-fold & $40 \mathrm{~ms}^{*}$ & $1300 \mathrm{~ms}^{*}$ & ND & {$[61]+$} \\
\hline GRAB-DA2h & DRD2 & $7 \mathrm{nM}^{*}$ & $280 \%$ * & 15-fold & $50 \mathrm{~ms}$ * & $7300 \mathrm{~ms}$ * & $500 / 520 \mathrm{~nm}$ & {$[61]+$} \\
\hline GRAB-rDA1m (red-shifted) & DRD2 & $95 \mathrm{nM}^{*}$ & $150 \%$ * & 15-fold & $80 \mathrm{~ms}^{*}$ & $770 \mathrm{~ms}^{*}$ & $565 / 595 \mathrm{~nm}$ & {$[61]+$} \\
\hline GRAB-rDA1h (red-shifted) & DRD2 & $4 \mathrm{nM}^{*}$ & $100 \% *$ & 10-fold & $60 \mathrm{~ms}$ * & $2150 \mathrm{~ms}^{*}$ & $565 / 595 \mathrm{~nm}$ & {$[61]+$} \\
\hline
\end{tabular}

DRD1,2,4: dopamine receptor 1,2 or 4 subtype; Exc: excitation wavelength; Emis: emission wavelength; $\mathrm{dFF}_{\max }$ : maximal increase in fluorescence between ligand-free and ligand saturated states; ND: not determined; * estimated in HEK-293 cells following bath or puff ligand application; ${ }^{* *}$ estimated in brain slices following 1 electrical pulse; + preprint (not peer-reviewed) at the time of this publication. 
Second, GPCR DA sensors have demonstrated a high specificity and affinity for their endogenous ligands, as well as rapid (tens of milliseconds) conformational change following receptor activation. This is because DA biosensors largely inherited the intrinsic properties of their native receptors, including affinity within physiological ranges (e.g., $765 \mathrm{nM}$ for dLight1.2, $90 \mathrm{nM}$ for GRAB-DA2m), molecular specificity (e.g., 70-fold specificity for DA over NE for dLight1.2, 22-fold for GRAB-DA2m) and rapid kinetics (e.g., $10 \mathrm{~ms}$ rise time for dLight1.2, $40 \mathrm{~ms}$ for GRAB-DA2m). We provide more details regarding intrinsic properties of sensors in Section 5 .

Third, DA biosensors are genetically-encoded and in that sense are ideally suited for incorporation into existing laboratory pipelines for in vivo genetic targeting. DA biosensor constructs are relatively small and thus could easily be packaged into AAVs (gene maximum size $4.4 \mathrm{~kb}$ ), leading to stable and strong expression in multiple brain regions thanks to strong promoters (e.g., CAG, hSyn). Transgenic animal models expressing DA biosensors are also being generated. For example, transgenic flies $[60,61]$ and zebrafish [60] carrying GRAB-DA sensors (and flies carrying the dLight1.3b sensor [61]) are available. Thus, thanks to genetic encoding through AAVs or transgenic expression, DA biosensors can in principle be chronically imaged for several months (although we recommend characterizing the system if expression must exceed 2 months, see Section 3.3). Longitudinal measurements can be advantageous when monitoring the effects of behavioral training, development, disease states or pharmacological treatments over long durations. Of note, chronic recordings are also possible with FSCV. However, one additional advantage of GPCR sensors is the ability to (in principle) track the same individual cellular ROIs over the course of an experiment when using cellular resolution imaging techniques such as miniscope imaging or 2-photon microscopy. Another major advantage is the ability to express GPCR sensors in specific cell types using cre-driver lines and flexed vectors. For instance, a flexed AAV for dLight1.1 was previously used to target DA 1 receptor (DRD1)-expressing neurons in the mPFC [98]. This may be particularly useful to compare the responses to DA between different cell types which express different DA receptor subtypes or for example between astrocytes and neurons.

Last, GPCRs represent the largest family of membrane receptors, covering most neurotransmitters and neuromodulators. This provides for many opportunities to engineer new sensors for other neuromodulators beyond the DA system (see e.g., Reference [118]) that will match as closely as possible the molecular specificity, affinity and kinetics of the endogenous receptor. Hence, GPCR biosensors for other neuromodulators such as acetylcholine [73,74], NE [71,72] and adenosine [76] have already been established, while more advanced versions of existing DA sensors [61] or preliminary sensors for serotonin (see Reference [119]), melatonin or opioids [58] are in development (for a review see: [118]). In that respect, many of the principles for sensor choice outlined in this review also apply to other neuromodulator sensors.

\subsection{Limitations of GPCR Dopamine Biosensors}

Importantly, there are several limitations that need to be acknowledged as end-users establish new sensors in the laboratory. First, there is a risk for GPCR sensors to buffer the endogenous ligand, that is, to reduce DA availability at wild-type DA receptors. This may be particularly true for high-affinity sensors capable of ligand binding in the nanomolar range (e.g., $\left.K_{d}<100 n M\right)$. Although high-affinity sensors may be ideally suited to capture DA transients of small amplitude or in brain regions with sparse innervation, the possibility for ligand buffering needs to be considered, especially after long periods of expression (e.g., several months). Ligand buffering is less of a concern in low affinity variants which have affinity in the micromolar range, which is likely to be higher than the local neuromodulator concentration. Of note, this would also not be the case for Periplasmic Binding Protein (PBP)-based sensors (another type of biosensor) such as iGluSnFR (glutamate), iGABASnFR (GABA) or iAChSnFR (acetylcholine) [120-122]; although a variant for DA remains to developed (see also [119,123] for a review on PBP sensors). For instance, to verify that dLight1 sensors do not buffer endogenous DA receptor function, we evaluated the effects of dLight1 expression on DA-induced cAMP signaling in cells endogenously expressing DRD1 (See next paragraph). Finding novel effective solutions to find a 
balance between the needed high affinity of a GPCR sensor required for imaging endogenous release in certain brain areas and the buffering/alteration of endogenous neurotransmitter signaling is an area of great interest for future sensor development studies.

Second, because they are built from membrane receptors, DA sensors may be capable of inducing GPCR downstream signaling cascades independently. There are multiple assays to investigate this, depending on the receptor type and its downstream G-protein dependent- (Gs, Gi, Gq and others) and independent- (e.g., beta-arrestin) coupling mechanisms. DRD1 is Gs-coupled and DRD2 is Gi-coupled and thus their endogenous activation increases and decreases cAMP levels, respectively. Thus, it was important to verify that the DRD1-based dLight1.1/1.2 sensors and the DRD2-based GRAB-DA sensors did not increase [58,59] and decrease [60,61] DA-dependent cAMP responses in HEK293 cells, respectively, as has been shown in References [58-61]. Additional G-protein coupling assays can include measuring cAMP levels in cells that endogenously express DA receptors as done for dLight1 and RdLight1 [58,59], monitoring cAMP in vivo in GRAB-DA-expressing animals [61] using the Pink Flamindo cAMP sensor [124] or assessing GTP- $\gamma$-S binding [60] (a proxy for G-protein downstream activity), as done for GRAB-DA. In addition, it is important to verify that DA sensors do not engage GPCR-dependent beta-arrestin downstream pathways, which would lead to sensor internalization. This was verified for dLight1/RdLight1 using a flow cytometry internalization assay and Total Internal Reflection Fluorescence (TIRF) microscopy to verify surface expression [58,59]. This was also verified for GRAB-DA sensors [60,61] using a beta-arrestin luminescent TANGO assay [125]. Of note, another advantage of PBP-based biosensors is that, as they are bacterial-derived, they do not induce downstream signaling in mammalian systems; thus, developing PBP-based DA sensors in the future is an area of great interest.

Related to this, unlike PBP-based sensors (or FSCV), GPCR-based DA biosensors are also sensitive to ligands that target the scaffold receptor on which they are built (e.g., DRD1, DRD2 or DRD4). This affects their ability to be used in combination with DA ligands; but may also in turn represent a useful tool for drug screening onto DA receptor subtypes. We expand on this topic in Section 5.6.

Moreover, it is worth noting the turnover of DA sensors has not been fully established. Hence, most of the GPCR signaling experiments were performed in short-term time-scales, minutes to days after DA-sensor genetic expression [58-61]. The absence of sensor internalization found in these studies implies that sensor expression will likely keep increasing over time which could lead to membrane overcrowding and possible toxicity or alterations in cell firing, as has been described for GCaMPs (see e.g., References $[7,9,126])$. Thus, if sensors need to be expressed chronically for many months, it would be advisable to reassess the absence of GPCR downstream signaling, as long-term sensor overexpression may affect these measures. A possible counter-solution to this would be to titrate the AAV titer to prevent overexpression.

It is also important to note that existing DA sensors are expressed ubiquitously throughout the membrane. One advantage of the membrane expression means that sensors sense DA transients only in close proximity to the postsynaptic cell of interest. This is different to FSCV and microdialysis which may also detect extra-synaptic DA dynamics. However, since membrane expression is ubiquitous, DA sensors do not necessarily reflect the exact location where DA receptors are located. Thus, end-users must keep in mind that dLight and GRAB-DA sensors may potentially detect levels of DA to which endogenous DA receptors may not be exposed to. Current models posit that DA is released through volume transmission, diffusing to many cells over large areas (5 to $12 \mu \mathrm{M}$ in normal animals $[127,128]$ ) and slow timescales, well beyond the synapse (striatal DA synapses are $<0.6 \mu \mathrm{m}$ in size; striatal intersynaptic distance: $3.5 \mu \mathrm{m}$ [128]) (for a review see References [90,95]). Thus according to this model, DA receptors (and dLight/GRAB-DA sensors) expressed extra-synaptically at large distances from presynaptic release sites may still detect DA (albeit at diluted concentrations [128]). However, emerging evidence indicates that DA release is highly heterogeneous, with variable release dynamics spanning slow and fast time scales [18,129] and hotspots of short-lived peaks of DA confined in space [57] as well as many silent release sites [95]. A better understanding of DA receptor location and DA release 
spatiotemporal heterogeneity is thus warranted to fully dissect DA spatiotemporal release dynamics in the brain. New and existing tools with high spatial resolution such as FFNs $[56,86]$ and carbon nanotubes [ 57,89$]$ and possibly DA biosensors as well [58] should allow us to answer some of these important questions. Moreover, future developments in the field of DA biosensors allowing to restrict sensor expression to synaptic sites instead of ubiquitously throughout the membrane could allow to further dissect these questions.

Related to this, current DA sensors also exhibit relatively low basal fluorescence levels (brightness). They have been successfully used in 2-photon and miniscope imaging experiments in mice [58] and Drosophila $[60,61]$, for example demonstrating heterogeneity of cortical DA release sites at high spatiotemporal resolution (17 $\mu \mathrm{M}$ ROIs) in mice. However, current sensors still lack the brightness to allow the identification of biologically relevant ROIs such as individual cells or dendritic spines. Future developments in this direction are thus warranted, following the steps of GCaMPs [8] or PBP sensors (e.g., iGluSnFr [120]).

\section{Regional Heterogeneity of Dopamine Systems Across the Brain}

In this section we will provide an overview of DA concentrations in rodent brains. We will also offer insights into what contributes to the divergence of reported values and will show why one single DA sensor is likely not suitable for application across all brain regions (see Sections 5.1.3 and 5.1.4).

We first included classical biochemistry data of DA/NE neurotransmitter levels in various brain regions. We next performed a literature search for results derived from in vivo brain microdialysis experiments and, when available, FSCV. It is worth mentioning here that the presented data is by no means intended to present a meta-analysis of different DA concentrations but is rather intended to give a brief overview on previously published DA concentrations across the rodent brain. We note that it may be useful for end-users to seek out further published work investigating DA levels in their brain ROI and animal model of interest, for example, rodents, zebrafish or drosophila [60,61].

\subsection{Mapping Dopamine Average Content Using Biochemistry}

We first looked at the biochemical content of DA/NE neurotransmitters throughout the brain to gain insights into which areas are likely to receive innervation from DA, NE or both. We focused on classical studies performed by Björklund \& Hökfelt [130] who quantified DA/NE content (ng protein/mg of tissue) using micropunches and enzymatic isotope assays. The main advantage of these biochemistry studies is the ability to gain a quick overview of the entire brain's neurotransmitter content in a molecular specific fashion (DE can be distinguished from NE). Such biochemical maps have been indispensable for early insights into DA/NE systems and later on for guiding tool development for DA/NE measurement in vitro or in vivo.Biochemical maps are presented in Figure 2, illustrating the divergent distribution patterns of DA (right-hand side of brain section) and NE (left-hand side) in the rat brain. Since the striatum contains dense levels of DA but weak levels of NE, it is widely accepted that electrochemical techniques such as FSCV performed in this brain region report DA signaling with negligible contribution of NE signals. It can be further appreciated from Figure 2 that a multitude of other regions in the rat brain receive DAergic inputs of varying magnitude. This fact illustrates that the requirements for DA sensors may vary largely across different brain regions. It needs to be emphasized, however, that these biochemical insights do not directly allow us to draw conclusions on the cellular compartment of DA/NE (e.g., cell body, axon, terminal) or release dynamics of such neurotransmitters. We refer to neuroanatomical mapping studies that provide useful complementary information regarding DA and/or NE cellular/axonal/terminal expression patterns throughout the brain $[45,131,132]$. More insights on in vivo release dynamics are provided in the next sections. 


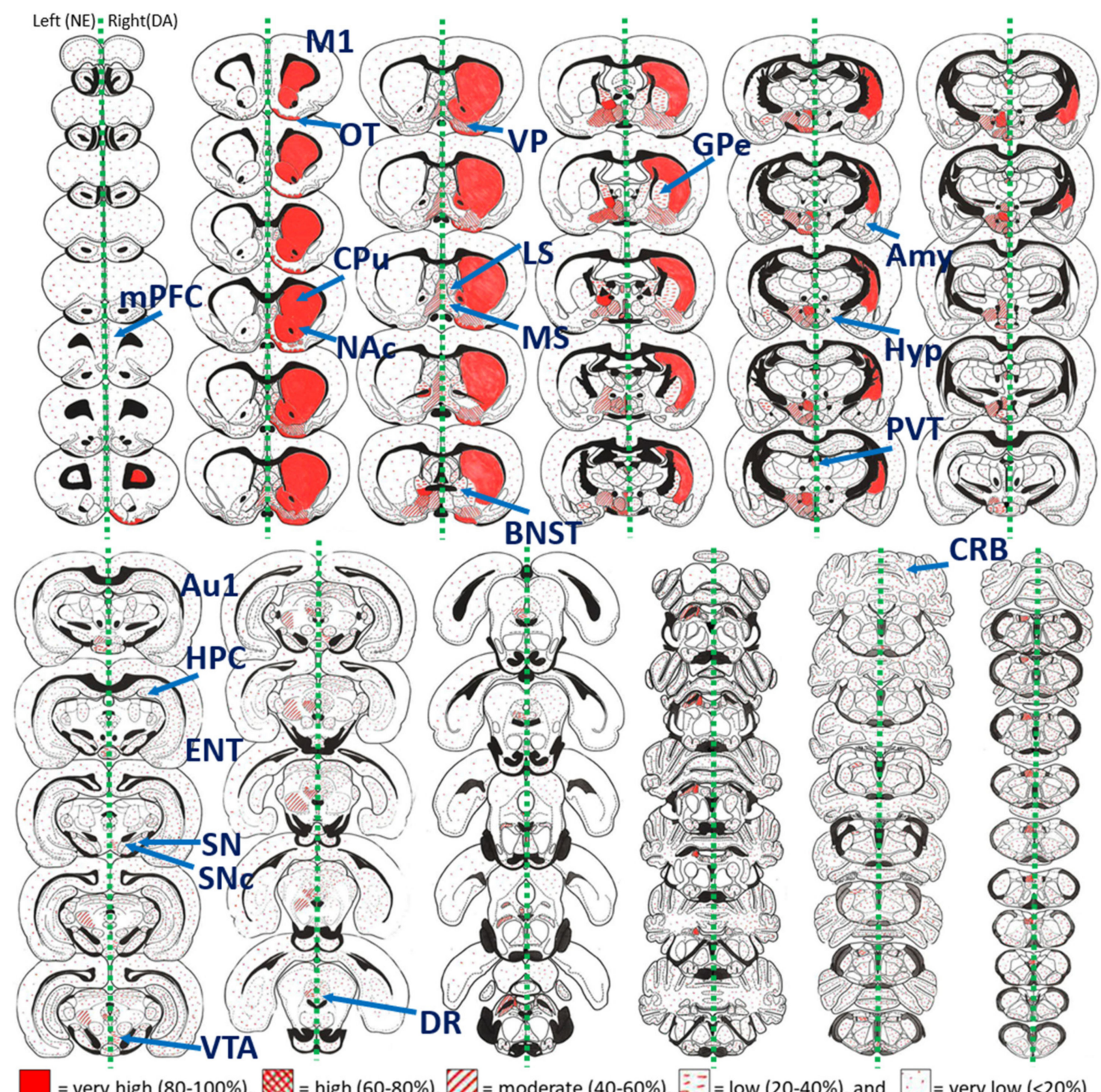

Left hemisphere: Norepinephrine - Right hemisphere: Dopamine

Figure 2. Distribution of norepinephrine (NE) (left hemispheres) and dopamine(DA) (right hemispheres) neurotransmitter levels as measured by enzyme isotope biochemistry assays in micropunches of the rat brain. The red fill pattern indicates the percentage of NE and DA relative to the highest measured value. NE: very high = greater than 64.0 ; high $=48.1-64.0$; moderate $=32.1-48.1$; low $=16.0-32.1$; very low $=$ less than $16 \mathrm{ng} / \mathrm{mg}$ protein. DA: very high = greater than 83.6; high $=62.7-83.6$; moderate $=$ $41.8-62.7$, low $=20.9-41.8$; very low = less than $20.9 \mathrm{ng} / \mathrm{mg}$ protein. Of note, the distribution pattern of DA and NE in the dorsal striatum and NAc is dramatically distinct-with DA content being very high (80-100\%), while NE content is very low (less than 20\%). Au1: primary auditory cortex; BNST: Bed nucleus of the stria terminalis; $\mathrm{CPu}$ : caudate-putamen (= dorsal striatum); CRB: cerebellum; DR: dorsal raphe; ENT: entorhinal cortex; GPe: globus pallidus externus; HPC: hippocampal formation; Hyp: Hypothalamus; LS: lateral septum; M1: primary motor cortex; mPFC: medial prefrontal cortex; MS: medial septum; NAc: Nucleus accumbens; OT: olfactory tubercle; PVT: paraventricular nucleus of the thalamus; SN: substantia nigra; SNc: SN compacta; TeA: temporal association cortex; VP: ventral pallidum; VTA: ventral tegmental area. For detailed brain region annotations see the original image source [130]. This Figure was modified with permission from Björklund \& Hökfelt (1984), Handbook of Chemical Neuroanatomy, Vol. 2-Part 1. (C) Elsevier Science Publishers B.V. (1984), Amsterdam, Netherlands [130]. 


\subsection{Mapping Basal Dopamine Levels Using In Vivo Microdialysis}

We next focused on in vivo microdialysis data obtained from a selection of rodent studies (Figure 3). The major advantages of microdialysis are: (i) its nanomolar sensitivity and (ii) its molecular specificity, allowing to distinguish DA from NE in microdialysis samples using HPLC. For more details on microdialysis techniques see Section 2.1. In Supplementary Table S1 we list basal DA concentration from different microdialysis studies across various brain regions including the reported parameters used [42,48,81,133-211]. Since microdialysis-derived values can vary greatly, we calculated the median values of all the reported basal DA concentrations for each brain region and normalized it to the median value derived from the dorsal striatum $(3.75 \mathrm{nM})$, presented in Figure 3. For details on the actual reported values per study and the parameters used, see Supplementary Table S1. Of note, the predicted basal DA level from asynchronous tonic firing has been reported around 10-30 nM [11,212], in the range of basal DA levels measured by microdialysis in the striatum/NAc (Figure 3).
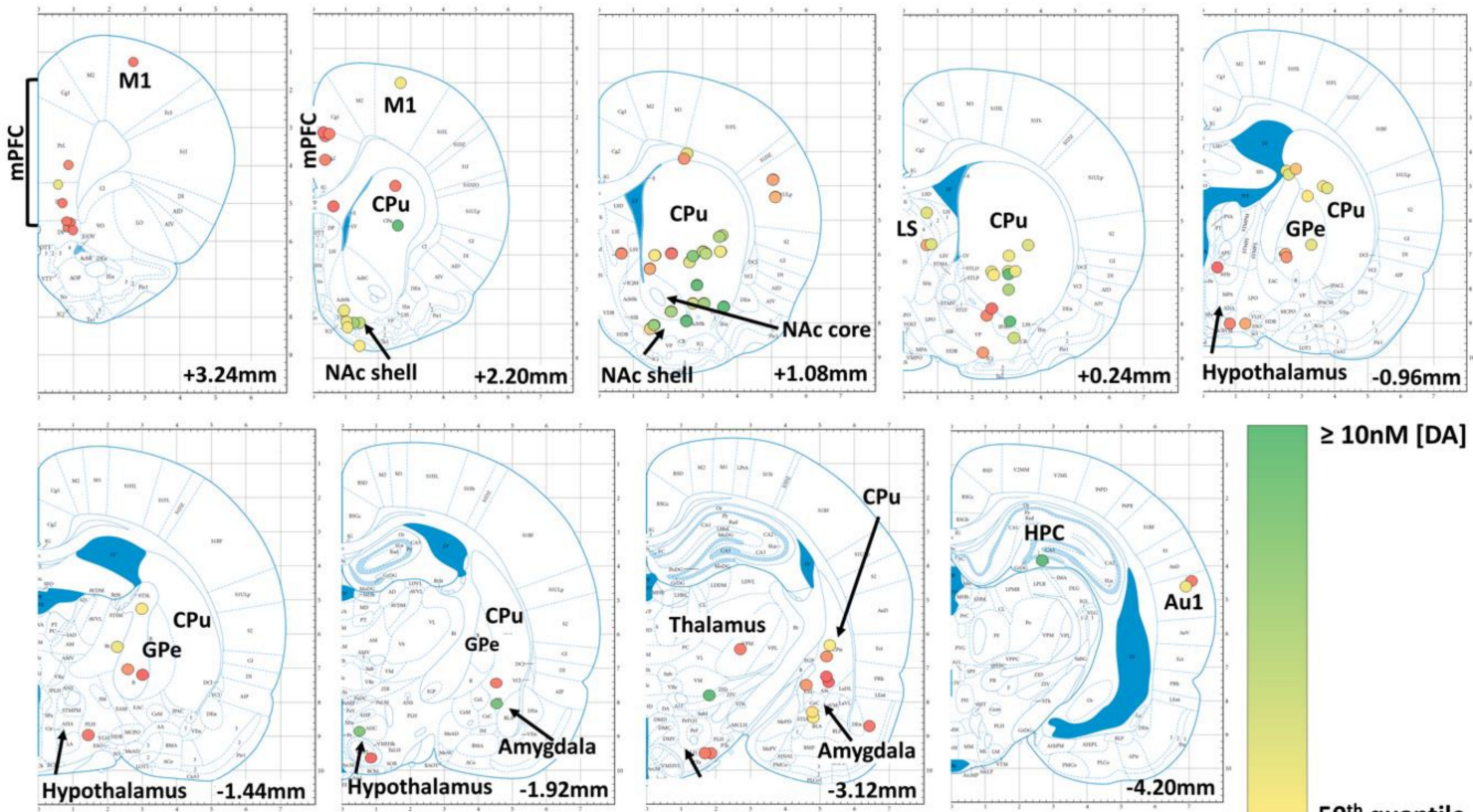

$\geq 10 \mathrm{nM}[\mathrm{DA}]$
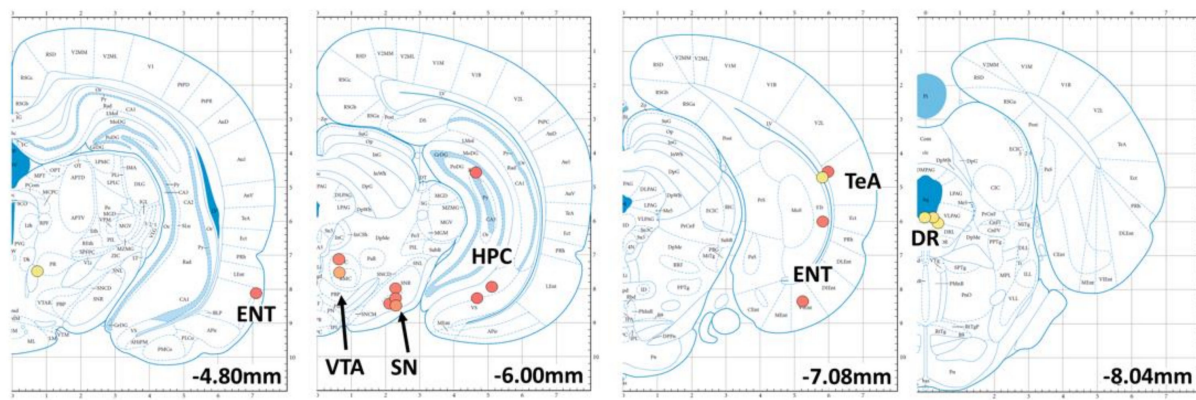

$50^{\text {th }}$ quantile

Figure 3. Graphical representation of previously reported basal dopamine concentrations measured via intracerebral microdialysis experiments performed in rats. Coronal brain sections from $\mathrm{AP}+3.24 \mathrm{~mm}$ to AP $-8.04 \mathrm{~mm}$ (relative to bregma) are depicted. The colored circles indicate the reported positions of the microdialysis probes and the fill color of the circles is color-coded to represent the values of the reported basal dopamine concentrations. Of note, the striatal basal dopamine concentrations are amongst the largest in rat brain (brain sections $\mathrm{AP}+1.08 \mathrm{~mm}$ and $\mathrm{AP}+0.24 \mathrm{~mm}$ ). Importantly, the basal dopamine levels do not represent phasic dopamine release since they are predominantly measured during baseline at rest and are a result of dialysate collection times in the range of several minutes. For detailed information on the previous studies reported in this analysis please consult Supplementary 
Table S1. This figure was modified with permission from Paxinos \& Watson (2005), The rat brain in stereotaxic coordinates, 5th edition. (C) Elsevier Academic Press (2005), Burlington, MA 01803, USA [213].

Based on this analysis, we found that basal DA levels in the NAc reached $\sim 62 \%$ relative to the dorsal striatum, followed by DA levels in the lateral septal nuclei ( $51 \%)$ and the dorsal raphe nuclei (40\%). The pallidum and ventral tegmental area (VTA) reached $\sim 21 \%$ and the amygdala $\sim 15 \%$ relative to the dorsal striatum. Furthermore, median values in the hypothalamus, thalamus, substantia nigra and cerebral cortices all were at $\sim 7 \%$ of the median dorsal striatal values. The lowest median DA concentrations reported in our selection were in the hippocampus with $\sim 3 \%$ relative to the dorsal striatum. In most of these referenced studies, basal DA concentrations were in the single-digit $\mathrm{nM}$ range. This illustrates that basal DA levels can reach 10-30 fold lower values as compared to the striatum in certain brain regions, further supporting the notion that different sensors will be best suited for individual brain regions according to sensor affinity.

It is worth noting, however, that microdialysis is limited in its ability to detect phasic DA release events. Our microdialysis maps (Figure 3) must therefore be interpreted with caution. Indeed, from our personal experiences and communication with other dLight1 users, we know that dLight1.1 and dLight1.3b perform well in the striatum, all the while having DA affinities (dissociation constants $\mathrm{Kd}$ ) of $330 \mathrm{nM}$ and $1.6 \mu \mathrm{M}$, respectively [58]. Hence basal DA levels reported by microdialysis (single-digit $\mathrm{nM}$ range) largely underestimate phasic DA release events (see Section 4.3).

This is due to the inherently slow time resolution of microdialysis due to long sample collection times. Considering that phasic DA release events are in the sub-second scale and are therefore only elicited in a subsection of the total microdialysis recording time (minutes), it is evident that averaging DA concentrations in microdialysis samples over several minutes will drastically diminish reported values and can therefore not represent the actual peak amplitudes of DA transients. Moreover, reported microdialysate concentrations depend on other parameters, including the extraction efficiency (i.e., relative recovery), which is influenced by the perfusion flow rate, dialysis membrane properties (e.g., active membrane length), probe geometry and physiological processes (transport, uptake, release, binding, metabolism) [214]. As these parameters must be optimized for the purpose of each individual experiment, there is a large heterogeneity in reported parameters and hence also in the reported DA concentrations, which hinders comparison between studies. For better transparency and comparability, we have reported most of these parameters in Supplementary Table S1.

\subsection{Insights into Phasic Dopamine Levels Using FSCV}

In a last step, we looked at FSCV studies measuring catecholamine levels in behaving rodents. The major advantages of FSCV are: (i) it allows us to track changes in metabolite levels with a much higher temporal resolution (subsecond) as compared to microdialysis, (ii) its nanomolar sensitivity and (iii) its quantitative nature (unlike DA biosensors [118]). Since FSCV captures fast catecholamine transients, the reported peak concentrations are usually much larger vs. microdialysis studies. One limitation of FSCV is that it does not distinguish DA from the closely related NE (see Section 2.1 for more details), so that reported levels report a mix of DA/NE release in regions with dual innervation. For an elegant strategy to counter this, see below and [23]. Note that the majority of studies using FSCV were performed in the NAc or striatum, with little work performed outside these brain regions due to the lack of molecular specificity. Thus, we did not have sufficient data to provide a reliable anatomical map. Werely on a few examples below to gain insights into the peak DA concentration range (nM) found in these regions under native and stimulated conditions.

For instance, native DA release concentrations were reported by Robinson et al., (2002): they found peak concentrations of $212 \mathrm{nM}$ and $290 \mathrm{nM}$ in the dorsal striatum and NAc, respectively, during social interactions of male and female rats [215]. Since this data was recorded in the striatum (with negligible NE innervation), the reported catecholamine levels can be considered as peak DA levels. Moreover, Hamid et al., (2016) reported increases in DA around 20 to $50 \mathrm{nM}$ in the rat NAc as rats 
approached rewards or upon reward cues [216]. Roitman et al., (2004) reported 50-100 nM DA release upon exposure to learned cues or lever presses [217]. Philips et al., (2003) found NAc DA increases around 50-150 nM during cocaine seeking behavior in rats [218]. Interestingly, Howe et al. (2013) found comparable levels (5-40 nM) of DA released in a prolonged manner (5-10 seconds ramps) as rats approached distant rewards [219]. There are only a few FSCV studies outside the striatum/NAc. Using an elegant approach Vander Weele et al. (2018) showed behaviorally-induced increases in catecholamines in the MPFC that can be attributed to DA. Indeed, authors found that a tail pinch led to a $20-40 \mathrm{nM}$ increase in catecholamines in the $\mathrm{mPFC}$, an effect that was largely blunted following photoinhibition of VTA DA neurons [23].

Of note, evoked DA release can also be measured upon stimulation of DAergic neuronal populations by either electrical or optogenetic stimulation to evaluate maximal DA release capacity. Peak DA concentrations elicited by these two modalities reach higher levels vs. native release, depending on the stimulation parameters applied. For example, Wightman et al., (2007) found DA concentrations reaching up to $1500 \mathrm{nM}$ in rats upon electrical VTA stimulation (2 ms, 24 pulses, $60 \mathrm{~Hz}, 125 \mu \mathrm{A}$ ) [220].Oleson et al., (2009) reported similar values obtained from mice after electrical VTA/substantia nigra pars compacta (SNc) stimulation ( $2 \mathrm{~ms}, 24$ pulses, $60 \mathrm{~Hz}, 120 \mu \mathrm{A}$ ) reaching $\sim 1000 \mathrm{nM}$ peak DA transients before single cocaine injection and $\sim 2000 \mathrm{nM}$ after a single cocaine injection [221]. Philips et al. (2003) also found increases in DA around 600-700 nM in the NAc following a similar electrical stimulation protocol (VTA, 24 pulses, $60 \mathrm{~Hz}, 120 \mu \mathrm{A}$ ) [218].

Using brief VTA optogenetic stimulation (10-ms pulses, 60 pulses, $30 \mathrm{~Hz}, 0.5 \mathrm{~s}$ epoch), Hamid et al., (2016) reported increases in DA around $120 \mathrm{nM}$ in the rat NAc [216]. Bass et al. (2010) reported a power-, pulse- and frequency-dependent release in the rat striatum following SNc optogenetic stimulation. For instance they found release around $45 \mathrm{nM}$ for weak stimulation protocols (e.g., 4-ms pulses, 20 pulses, $20 \mathrm{~Hz}, 1 \mathrm{sec}$ epoch) and up to $500 \mathrm{nM}$ for strong stimulation protocols (20-ms pulses, 60 pulses, $60 \mathrm{~Hz}, 0.5$ to 1 sec epoch) [222]. Moreover, VTA optogenetic stimulation (60 pulses, $20 \mathrm{~Hz}$ ) also led to DA release around $40 \mathrm{nM}$ in the $\mathrm{mPFC}$ [23]. Interestingly, optogenetic stimulation of DA neurons in Drosophila using continuous ( 3 to 7 s) blue light led to comparable DA levels (600-800 nM, measured by FSCV [223]) as in the rat. Whether behaviorally-induced release of DA in these two species is also similar or whether they differ remains to be investigated.

\section{Practical Considerations for Sensor Choice: One Sensor Does Not Fit All}

For end users, choosing the most appropriate sensor for a given experimental application is paramount. In Section 4, we mapped DA levels across multiple brain regions in rodents as a guide for future users. Local DA levels can be a useful measure to optimize sensor choice based on ligand affinity. Dynamic range and molecular specificity are other key parameters to consider. We outline below how these sensor properties are measured and how they can guide sensor choice. Moreover, behavioral constraints, imaging acquisition methods (fiber photometry, 1 and 2-photon micro/endoscopy, etc.), multiplex experiments and pharmacological paradigms may further affect sensor choice based on other sensor properties including: kinetics, brightness, spectrum and molecular scaffold, which we further discuss below.

\subsection{Matching Brain Region Dopamine Levels to Sensor Affinity and Dynamic Range}

\subsubsection{Affinity}

The sensitivity of a GPCR sensor for its neuromodulator, such as DA, primarily depends on two main properties: its affinity and dynamic range. The ligand affinity of a sensor corresponds to the neuromodulator concentration required to reach half the maximal fluorescent response (also referred to as dynamic range, dFFmax) and is expressed as an apparent dissociation constant $\left(\mathrm{K}_{\mathrm{d}}\right)$ or half-maximal effective concentration $\left(\mathrm{EC}_{50}\right)$. Figure 4 outlines how affinity and dynamic range can be calculated. Ligand affinity gives an indication of the physiological concentration of DA at which the sensor will be 
most sensitive and can thus help in the selection of sensors for in vitro or in vivo applications based on regional DA concentrations (see Section 4 for our in vivo estimates in rodents).

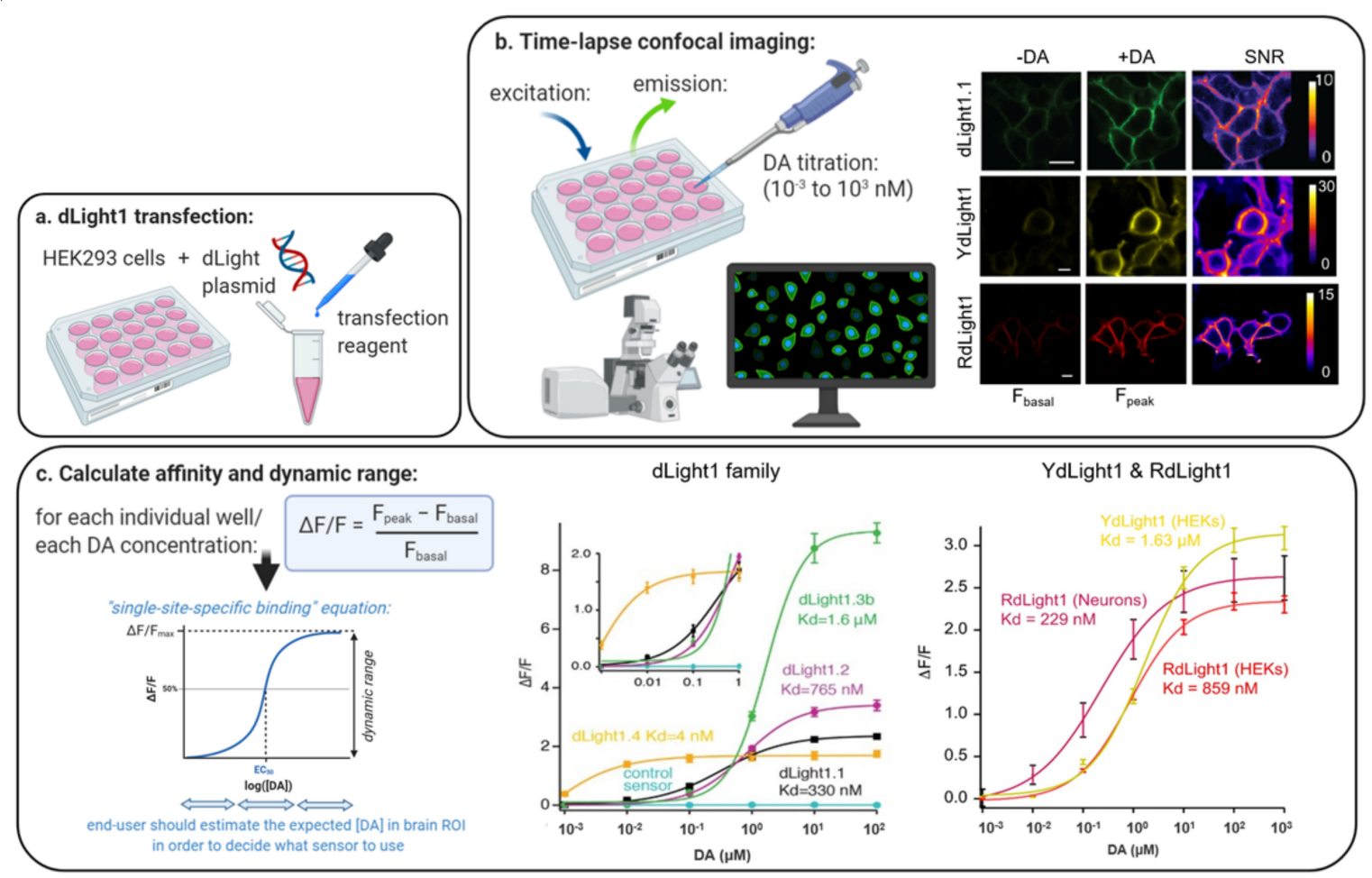

Figure 4. Concentration-response curves to determine affinity $\left(\mathrm{K}_{\mathrm{d}}\right)$ and dynamic range $\left(\mathrm{dFF}_{\max }\right)$ of dopamine (DA) biosensors in vitro. (a) In a first step, HEK293 cells are transfected with the DA sensor plasmid of interest. (b) After 2 days of sensor expression, sensor fluorescence is measured in response to DA titrations $\left(10^{-3}\right.$ to $\left.10^{3} \mathrm{nM}\right)$ which are perfused into the bath during time-lapse confocal imaging with $488 \mathrm{~nm}$ (dLight1, YdLight1) or $561 \mathrm{~nm}$ (RdLight1) light. Time-lapse images of fluorescent cells before and after addition of increasing DA concentrations are obtained and used to calculate the signal to noise ratio (SNR) and average fluorescence intensity (F). (c) dFF is calculated using the following equation: $[\mathrm{F}$ (peak)-F(basal)]/F(basal) where $\mathrm{F}$ (basal) and $\mathrm{F}$ (peak) are the averaged fluorescence intensity of 10 frames before and after, addition of a given DA concentration, respectively. Maximal dFF values for a given concentration are plotted and a single-site-specific binding equation is used to fit the data points and determine the affinity $\left(\mathrm{K}_{\mathrm{d}}\right.$ value) and $\mathrm{dFF}_{\max }$ of the sensor for this ligand (titration data shown in panel c are from References [58,59]). For further details on the protocol, see Reference [99].

In an ideal scenario, multiple sensor variants will exist covering a broad range of affinities and dynamic ranges to match the demands of each individual system or brain region being studied. Currently, sensors have been successfully engineered against DRD1 (dLight1.1, 1.2 and 1.3, YdLight1, RdLight1), DRD2 (dLight1.5 and all GRAB-DA sensors) and DRD4 (dLight1.4) as the GPCR molecular scaffold, but not yet for the DRD3 and DRD5 subtypes due to expression issues [58]. The molecular scaffold directly affects the sensor affinity and dynamic range. One main advantage of using native GPCRs as the molecular backbone, is that they leverage the evolutionary specificity for the ligand of choice and thus naturally lead to affinities well within the physiological range (as opposed to bacterial PBP-based sensors [123]). As shown in Table 1, the dLight1/RdLight1 family covers affinities from very high, single-digit nanomolar affinities (e.g., dLight1.4: 4nM), high (dLight1.5), medium (e.g., dLight1.1, 1.2; RdLight1) and low (dLight1.3a, 3b; YdLight1) affinities [58,59]. GRAB-DA sensors also include very high (DA1h, DA2h, rDA1h) and high (DA2m, rDA1m, DA1m) affinity variants [60,61] (Figure 5). 
a.

Sensor affinity



Figure 5. Sensor properties to consider for sensor choice: (a) Local dopamine (DA) levels can be a useful measure to guide sensor choice based on ligand affinity. It is generally recommended to look at sensor affinity as a first criterion and to match it with the local expected concentration of DA in the brain ROI, using high and very high affinity variants for regions with sparse innervation and medium/low affinity variants for regions with dense innervation; here we classify existing DA sensors based on their affinity category (affinity $\mathrm{K}_{\mathrm{d}}$ and dynamic range $\mathrm{dFF}_{\max }$ are noted in brackets). (b) Other sensor properties should be considered (see also Table 1 for exact values) and their relative importance will depend on the individual experimental parameters: (i) dynamic range (if possible at least 250-300\%), (ii) molecular specificity (affinity for DA should be far greater than affinity for NE in brain regions with dual DA/NE innervation), (iii) on and off kinetics (should be as short as possible in assays where high temporal resolution is required), (iv) basal brightness (may not matter for fiber photometry but high brightness may improve identification of small cell compartments in 1- and 2-photon imaging), (v) color spectrum (3-colors available; important when multiplexing with opsins, sensors or photopharmacology) and (vi) molecular scaffold (3-scaffolds available; important when multiplexing with (photo)pharmacology: if drug has affinity for the DA receptor scaffold, signal may be affected; this property can however be harnessed in drug discovery experiments where sensor fluorescence can be used as a specific readout of DA receptor subtypes activation in vitro or in vivo).

\subsubsection{Dynamic Range}

The dynamic range $\left(\mathrm{dFF}_{\max }\right)$ is defined as the ratio between the estimated maximal fluorescent response upon ligand addition and the baseline fluorescent level (before ligand addition) (Figure 4). It thus provides an estimate of the range of responses that can be obtained against varying DA concentrations. A large dynamic range critically determines a sensor's sensitivity to small and large fluctuations in DA levels. In our original publications, we found dLight1/RdLight1 variants to exhibit close to $200 \%$ and up to $900 \%$ dynamic range [58,59], matching levels found for PBP-based sensors [119]. 
Although the first generation of GRAB-DA sensors (DA1h, DA1m, rDA1h, rDA1m) exhibited a 2 to 10 -fold lower dynamic range vs dLight sensors, the second generation provides enhanced levels $(340 \%$ for DA2h, 280\% for DA2m) [60,61] (Figure 5).

Affinity and dynamic range are typically assessed in HEK293 cells expressing the GPCR sensor by measuring fluorescent responses (dFF) in response to bath application of increasing (pM to $\mu \mathrm{M}$ ) concentrations of DA followed by data fitting against a single-site specific binding equation or a Hill Equation (see e.g., Reference [58]) (Figure 4).

\subsubsection{Sensor Choice Based on Affinity and Dynamic Range}

For future sensor users, it is generally recommended to look at sensor affinity as a first criterion and to match it with the local expected concentration of DA in the brain ROI (Figure 5). This is especially true in experiments looking at behavioral-induced DA release. This may be less essential in experiments solely focusing on electrically- or optogenetically-evoked DA release, where detected DA levels are often found to be several fold higher as compared to endogenous release (see Section 4.3). Next, among the sensors selected, it is best to favor a sensor with maximal dynamic range (if possible, $>250-300 \%$ ). We found that dLight1.1, dLight1.2 and RdLight1 displayed an optimal combination of medium ligand affinity $(330 \mathrm{nM}, 765 \mathrm{nM}$ and $860 \mathrm{nM}$, respectively) and good dynamic range (230\%, $340 \%$ and $250 \%$, respectively), making them ideally suited for in vivo bulk (photometry) imaging of large DA transients in response to rewards or cues in the heavily innervated striatum or NAc [58,59], see also: $[107,110-113,115,224,225]$. On the other hand, sensors with high and extremely high affinity such as GRAB-DA2m $\left(K_{d}=90 \mathrm{nM}\right.$; dFFmax $=340 \%$; validated in vivo), GRAB-DA2h $\left(K_{d}=7 \mathrm{nM}\right.$; $\mathrm{dFFmax}=280 \%$; validated in vivo) [61] and dLight $1.4\left(\mathrm{~K}_{\mathrm{d}}=4.1 \mathrm{nM}\right.$; dFFmax $=170 \%$; not validated in vivo yet) [58]; as well as other sensors in development (not shown) are ideally suited to detect DA release in brain regions with sparser and extremely sparse innervation or may potentially be used to track tonic DA changes in the nanomolar range [11] (this remains to be determined). Their in vivo applications in such brain regions remains to be demonstrated, however, along with their ability to distinguish DA from NE when dual innervation patterns arise (see next section on Molecular specificity). These sensors may also work in densely innervated regions, albeit some possible saturation upon strong DA release events. Finally, dLight1.3a and dLight1.3b variants display a combination of low affinity $\left(\mathrm{K}_{\mathrm{d}}>1000 \mathrm{nM}\right)$ but very higher dynamic ranges $(2-3 \times$ higher than that of dLight 1.2$)$. dLight1.3b has already demonstrated its use in vivo in the NAc using fiber photometry $[101,108,226]$. Because of the higher threshold of DA concentration required for sensor activation, these sensors are less well suited for brain regions with low DA. However, by remaining insensitive to small DA variations (e.g., tonic DA variations or variations arising in more sparsely innervated sites) but responding with large signals where DA is heavily released (e.g., in response to highly salient behavioral stimuli or in subregions heavily innervated) these variants may be ideally suited to detect and visualize DA release hotspots using miniscope, 2 photon or even mesoscopic techniques, although these applications remain the be tested for this purpose. Moreover, combining medium affinity variants (e.g., RdLight1) with low affinity variants (e.g., dLight1.3b) may allow other people to gain a deeper understanding of the spatiotemporal dynamics of DA release, diffusion and uptake.

Note there is the distinct possibility for high-affinity sensors (nanomolar range) to bind DA and induce ligand buffering, especially after long periods of expression (e.g., several months). Ligand buffering is less of a concern in low affinity variants (micromolar range) with affinity values higher than the local neuromodulator concentrations. Developing novel sensors with the perfect balance of high affinity and low risk for ligand buffering is an area of great interest for future studies.

\subsubsection{Published In Vivo Validations of DA Sensors in Brain Regions with Dense vs. Sparse Innervation}

In Supplementary Table S2 we present an overview of previously published in vivo applications of DA biosensors from the dLight, RdLight and GRAB-DA families in rodent animal models $[38,58,60,61,98,101-116,224,226-228]$. The large majority of experiments was performed in 
either the dorsal striatum or the NAc where the DA concentration reaches its maximal levels. Studies have successfully used high, medium and low affinity DA variants in these regions (see Figure 5), although the medium variants (e.g., dLight1.1/1.2) are the most commonly used. High-affinity variants could help detect subthreshold DA release dynamics but are likely to saturate while low-affinity variants could be useful to detect hotspots but will omit smaller DA transients. Based on our brain maps, we predict that medium affinity variants are likely to work well in other brain regions with high DA content, that is, the olfactory tubercle.

DA biosensors have also successfully been put to use in brain regions with medium to low DA, albeit with reduced signal to noise ratio. This includes the frontal/motor cortex (dLight1.1 \& 1.2) [58], the mPFC (dLight1.1) [98], the basal (dLight1.1 \& 1.2) and central (GRAB-DA2m) amygdala [38,98,103] and the bed nucleus of the stria terminalis (GRAB-DA2m) [38]. These studies used sensors with medium to high affinities (90-765 nM) for DA and maximal dFF between 230-340\%.

In future work, recently developed sensors with very high affinities (GRAB-DA2h, -rDA1h and dLight1.4) could improve signal detection in these brain regions. To the best of our knowledge, very high-affinity sensors have thus far not been applied outside of the striatum in vivo. This might be due to the lower $\mathrm{dFF}_{\max }$ values reached by these sensors. The candidate with the largest $\mathrm{dFF}_{\max }$ value $(280 \%)$ within the group of very high affinity DA-sensors is GRAB-DA2h and might at this point be the most likely candidate to be successfully applied in vivo in brain regions with low DA innervation. One exception are brain regions with dual DA/NE innervation like the MPFC where dLight variants are preferred (see Section 5.2).

Upon comparison with our anatomical DA concentration maps (see Figures 2 and 3 and Supplementary Table S1), we propose that existing high and very high affinity DA biosensors are likely to perform well in brain areas with moderate or low DA levels (e.g., ventral pallidum, dorsal raphe, amygdala, medial and lateral septum, hippocampus, cortex or GPe). This needs to be tested empirically, however, given the limitations of our biochemistry/microdialysis maps (See above). Medium affinity variants may also work in these regions but likely with a weaker signal (lower dFF). Future work is warranted to further boost the dynamic range of high and very-high affinity DA-sensors for these applications.

\subsection{Sensor Molecular Specificity Matters in Brain Regions with Dual Dopamine/Norepinephrine Innervation}

Another property to take into consideration includes the sensors' ligand specificity for DA over NE (and other monoamines), as the chemical structure of DA vs. NE is very similar. For instance, DA and NE only differ by one hydroxyl group [229] and many currently available methods to record DA release such as FSCV, FFNs or carbon nanotubes cannot differentiate DA from NE. To determine sensor molecular specificity, DA sensor affinity for other monoamines such as NE can be titrated in HEK293 cells using the same methods as described in the previous section. Doing this, the affinity for DA over NE was found to be 70-fold higher for dLight1.1 [58], 60-fold higher for RdLight1 [59] and 270-fold higher for dLight1.3 b [101]. Further, dLight1.1 affinity for DA over epinephrine was 40-fold higher and responses to other neuromodulators were negligible. Thus, one of the main advantages of dLight1 GPCR sensors over other available methods is the ability to reliably distinguish DA from NE. This is particularly relevant in brain regions that harbor dual innervation of both DA and NE systems, such as the mPFC [23] or the PVT [39], among others. Notably, molecular specificity of all GRAB-DA sensors for DA over NE was 10 to 20-fold. In the striatum and NAc, where NE innervation is negligible [230], first and second generation GRAB-DA sensors are likely to be highly specific to DA. However, when considering experiments in other brain regions, careful estimations of NE basal and evoked levels must be made. For instance, in the mPFC, basal levels of NE are in the single-digit nM range but evoked NE levels can be found in the several hundreds of $\mathrm{nM}$, often found to be higher than DA levels, depending on the context $[23,231-234]$. Thus it is important to keep in mind that the high-affinity variants DA1h, DA2h and rDA1h have a ligand affinity for $\mathrm{NE}$ around $100 \mathrm{nM}$, which is likely to detect $\mathrm{NE}$ in the $\mathrm{mPFC}$, although this remains to be tested (Of note: medium-affinity variants DA1m, DA2m 
and $\mathrm{rDA} 1 \mathrm{~m}$ sensors have a ligand affinity for $\mathrm{NE}$ around 1 to $2 \mu \mathrm{M}$ ). In contrast, the medium-affinity dLight1.1 variant had an affinity for NE at 19,850 nM [58]. When in doubt, DA sensors responses can be titrated ex vivo and in vivo in response to noradrenergic drugs and/or locus coeruleus optogenetic stimulation to ascertain molecular specificity.

\subsection{Maximizing Sensor Kinetics Allows to Sparse out Individual Transients in Response to Closely Related Stimuli}

The rise ( $t_{1 / 2}$ rise) and decay ( $t_{1 / 2}$ decay) times represent the times required by the sensor to (1) reach half of the peak activity following acute stimulation and (2) return to half of the basal level prior to simulation. The in vitro on- and off-kinetics of the first generation of dLight1 sensors are excellent (e.g., dLight1.1: $\mathrm{t}_{1 / 2}$ rise: $10 \mathrm{~ms}$ and $\mathrm{t}_{1 / 2}$ decay: $100 \mathrm{~ms}$; RdLight1: $\mathrm{t}_{1 / 2}$ rise: $14 \mathrm{~ms}$ and $\mathrm{t}_{1 / 2}$ decay: $400 \mathrm{~ms}$ ) surpassing existing GCaMP sensors (e.g., GCaMP7f: $\mathrm{t}_{1 / 2}$ rise: $27 \mathrm{~ms}$ and $\mathrm{t}_{1 / 2}$ decay: $265 \mathrm{~ms}$ ). Moreover, dLight1.1 and RdLight1 kinetics were also evaluated in vivo, demonstrating highly accurate reporting of individual stimulation events in the NAc at $5 \mathrm{~Hz}$ (dLight1.1) and $2 \mathrm{~Hz}$ (RdLight1) and good reporting at $10 \mathrm{~Hz}$ (dLight1) and $4 \mathrm{~Hz}$ (RdLight1) following VTA optogenetic stimulation (2 s total) $[58,59]$ (see also Figure 1). In vitro on-kinetics of GRAB-DA sensors are in the same order of magnitude as dLight1.1/1.2 (e.g., GRAB-DA2m: $\mathrm{t}_{1 / 2}$ rise: $40 \mathrm{~ms}$ ) but off-kinetics are 7 to 70 times higher as compared to dLight1 (e.g., GRAB-DA1m: $\mathrm{t}_{1 / 2}$ decay: $710 \mathrm{~ms}$ ), making them less attractive to detect rapidly succeeding DA transients. We must acknowledge, however, that on and off kinetics are measured using different methods across laboratories, making it difficult to make precise comparisons. The on- and off-kinetics of dLight sensors were measured following electrical stimulation in brain tissue $[58,59]$ where endogenous reuptake mechanisms can rapidly decrease DA concentrations and in turn reduce off-kinetics. This contrasts with GRAB-DA sensors where the same properties were measured following a DA puff in HEK293 cells that lack these rapid reuptake mechanisms [60,61].

On- and off-kinetics are critical parameters to consider when choosing sensors. Using sensors with short on- and off-kinetics is most important in assays where high temporal resolution is needed and acute DA transients are expected (alternatively, one could consider changing the behavioral parameters to fit the kinetics of the sensor of interest). For instance, behavioral tasks assessing reward behavior encompass cues followed by reward delivery which often occur within a few seconds from each other. Based on the in vivo frequency-dependency experiments outlined above, we expect dLight1.1 and RdLight 1 to track events with intertrial intervals of up to 0.5 and 0.2 seconds, respectively; at least under the experimental conditions used in References $[58,59]$. On the other hand, slower sensor kinetics may presumably allow to detect smaller DA transients via summation and signal integration; this needs to be accounted for during data interpretation but may improve sensitivity (although this remains to be tested empirically). This would be akin to GCaMP6s (or GCaMP7s) which demonstrated slower kinetics vs. GCaMP6f (or GCaMP7f) but higher sensitivity (= higher response to 1 or 10 AP trains) and is partly due to their 2-3 fold higher affinity for calcium [7,8]. Moreover, DA transients can also encode slower variables such as spontaneous movements across several seconds [58,94]. DA transients can also ramp up over several seconds in freely moving animals approaching rewards or running to distant goals following cues $[94,101,105,216]$. Here fast on/off-kinetics are useful to identify more precisely the boundaries of the transient; however slow off-kinetics may allow to detect smaller fluctuations in DA, that could otherwise be occluded. In such complex cases the best sensor remains to be determined empirically. For an interesting perspective on sensor kinetics, see Reference [235]. Of note, in assays where fast off-kinetics are less of a concern (e.g., to track slow changes over minutes/hours or measure changes in tonic levels), other sensor properties can be prioritized instead of kinetics. For example, a recent study found that injection of heroin to naïve animals induced an increase in DA release in the NAc within minutes following injection; in this experiment, fast kinetics were not required [110].

Moreover, in experimental paradigms aiming at addressing the dual dynamics of two neurotransmitters simultaneously and their possible causal relationships (e.g., DA and NE in the mPFC or DA and acetylcholine in the NAc), it would be important to choose two sensors with similar 
kinetic profiles (see Reference [119] for the most recent summary table of neuromodulator sensor kinetics). Currently, many of the neuromodulator sensors differ by up to a factor of 70 in their onand off-kinetics (see comment above regarding caveats in comparing sensor kinetics). This makes it difficult to interpret possible bidirectional relationships. One option is to measure the kinetics of the chosen sensors in slice or in vivo following optogenetic or electrical stimulation to determine the lag of one sensor against the other and in turn apply corrections in subsequent analyses. When dual sensor kinetics are too different from each other, another solution is to use axon-GCaMP6f as a common denominator. For instance, one could determine relative dynamics of axonal activity of DA vs. NE afferents into the mPFC using axon-GCaMP6f; before using DA vs. NE biosensors to measure relative release dynamics. For example, we found high fidelity between axonal calcium levels arising from the midbrain (measured with axon-GCaMP6f) and DA release (measured with RdLight1) in the NAc in a reward task [59].

\subsection{Future Developments in Sensor Brightness/Subcellular Expression will Improve 1 and 2-Photon Imaging}

DA biosensors have the potential to be deployed across multiple in vivo imaging modalities such as multiplex fiber photometry, 1-photon miniscope imaging and 2-photon regular or mesoscopic imaging and recordings can be performed repeatedly across multiple days (for details on these techniques, see References $[62,68,69])$. DA sensors work optimally for rodent fiber photometry and hence the majority of published work thus far was performed using this method. Indeed, the affinity, dynamic range and basal brightness levels of the first generation of DA sensors were found highly appropriate for fiber photometry applications, as demonstrated across multiple experiments and publications [38,58,60,61,98,101-106,108-115]. For fiber photometry, low basal fluorescence and high evoked fluorescence is preferred to optimize response detection.

Notably, dLight1 has successfully been used to identify DA transients across the striatum and cortex using 2-photon imaging (Figure 1) [58].GRAB-DA1 and 2 sensors have also been used in drosophila to perform 2-photon imaging [60,61]. 2-photon imaging of dLight1.1 transients (Figure 1) demonstrated heterogeneity of cortical DA release sites as defined across $17 \mu \mathrm{M}$ ROIs in mice. Thus, sensors were bright enough to identify behaviorally relevant fluorescent responses. Although dLight1.3b has not been validated in 2-photon imaging, we speculate that, due to its low affinity $(1600 \mathrm{nM})$ and very large dynamic range (930\%), it may be well-suited to detect and visualize DA release hotspots in densely innervated regions using these imaging techniques. However, it must be noted that, in published 2-photon experiments [58], it was not possible to define biologically-relevant ROIs such as individual cells or dendritic spines. Moreover, 2-photon transients were pooled across the field of view $[58,60,61]$. One possible solution to this caveat would be to increase both the basal and evoked brightness of existing sensors, as well as the surface expression, thus allowing to improve the detection of cellular compartments. Such tool engineering approaches have recently been implemented for calcium sensors, with the development of the bright calcium sensor GCaMP7b, engineered to provide increased resting and evoked fluorescence to allow improved imaging of small processes such as boutons [8]. Similar developments to enhance the brightness of DA sensors are ongoing, as shown in a recent preprint for the GRAB-DA2m sensor [61], which, however, remains to be validated in 2-photon rodent imaging assays. Another solution would consist in targeting the sensor to specific subcellular compartments (e.g., dendrites), as has been done recently by Broussard et al., where GCaMP6f was fused to the axon motif GAP43 to drive axonal localization and improve 2-photon presynaptic imaging [52].

\subsection{Sensor Color Spectra Permits Dual Imaging and Multiplexing with Optogenetics and Photopharmacology}

Another important factor to consider is the sensor color spectra. Given that the green DA sensors dLight 1 and GRAB-DA1 and 2 were engineered using cpGFP, that is, the same fluorescent monomeric protein as GCaMPs, it is not surprising that the spectral properties are highly similar $[7,8]$. Using one-photon emission spectra in HEK293 cells (dLight1, GRAB-DA2) and awake mice (GRAB-DA1), authors identified peak emission around $517 \mathrm{~nm}$ for dLight1, $510 \mathrm{~nm}$ for GRAB-DA1 and $520 \mathrm{~nm}$ for 
GRAB-DA2 sensors following excitation at $488 \mathrm{~nm}$ (dLight1) and $470 \mathrm{~nm}$ (GRAB-DA1). Moreover, two-photon emission spectra for dLight1 peaked at $920 \mathrm{~nm}$. The isosbestic point (=excitation wavelength at which sensor absorbance does not change in response to DA) for GRAB-DA2 $h$ is $440 \mathrm{~nm}$ [61] as determined by one-photon excitation spectra. Isosbestic points were not formally generated for dLight1 and GRAB-DA1; however, several laboratories determined empirically that dLight1 is insensitive to $405 \mathrm{~nm}$ excitation light in vivo (see e.g., raw traces in Supplement 1 Figure 1 in Reference [115]). For more details on isosbestic channels and their limitations, see Reference [62]. Similarly, red-shifted sensors RdLight1 and GRAB-rDA1 yielded emission spectra with minimal overlap with green sensors and highly comparable to red-shifted calcium sensors like jRGRECO1a (all using cpmApple as the chromophore). Peak emission is at $588 \mathrm{~nm}$ (RdLight1) and $595 \mathrm{~nm}$ (GRAB-rDAs) following $561 \mathrm{~nm}$ (RdLight1) and $565 \mathrm{~nm}$ (GRAB-rDAs) excitation (isosbestic points remain to be determined in future work).

Sensor color spectra is important to consider when multiplexing DA imaging with other methods such as optogenetics, calcium/neurotransmitter imaging or photopharmacology. Previous work by us and others found that the green sensors dLight1.1 (Figure 1), dLight1.3b, GRAB-DA1h, $1 \mathrm{~m}$ and DA2 $h, 2 m$ are compatible with red-shifted optogenetic stimulation using fiber photometry in rodents. Hence, robust increases in fluorescence in the NAc or dorsal striatum were detected in response to VTA or SNc red-shifted (ChrimsonR, C1V1) optogenetic stimulation [58,60,61,226]. Moreover, we found that RdLight1 is compatible with optogenetic stimulation with the green opsin ChR2 (Figure 1) [59]. Green and red sensors were also compatible with two color imaging, due to their orthogonal spectra. For instance, green dLight1.1 was successfully imaged in combination with the red-shifted calcium indicator jRGECO1a [77] (Figure 1) [58]. RdLight1 was imaged in the NAc in combination with multiple green sensors including axon-GCaMP6f [52] to image arising VTA DA terminals or mPFC terminals, GCaMP6f [7] to image DRD1-expressing neurons in the striatum and iGluSnFR [120] to image incoming glutamatergic inputs [59]. As mentioned previously (Section 5.3), when imaging two sensors simultaneously, sensor kinetics should be matched as closely as possible to optimize data interpretation; for instance we found that axon-GCaMP6f imaging of VTA axons and RdLight1 imaging of DA release were highly correlated during a reward task [59], which is consistent with their relatively similar kinetics (RdLight1: $\mathrm{t}_{1 / 2}$ rise: $14 \mathrm{~ms}$ and $\mathrm{t}_{1 / 2}$ decay: $400 \mathrm{~ms}$; untargeted-GCaMP6f: $\mathrm{t}_{1 / 2}$ rise: $45 \mathrm{~ms}$ and $\mathrm{t}_{1 / 2}$ decay: $140 \mathrm{~ms}$ [7]). We do expect that VTA axonal activity (axon-GCaMP6f) and DA release (RdLight1) may be decorrelated under certain conditions, for instance when activating nicotinic acetylcholine receptors (nAchR), which are known to modulate DA release partly independently of DA axon activity (see e.g., Reference [11]).

Moreover, in principle, green and red sensors should also be compatible with recently developed photopharmacological tools, such as Opto-XRs, that permit region or cell-specific pharmacological manipulations of desired receptors or ion channels in combination with light (for a recent review, see: [236]), although their combined applications in vivo remains to be tested. For instance, blue light illumination of a chimeric rhodopsin-DRD1 receptor (Opto-D1R) expressed in NAc DRD1-expressing cells increased DRD1-expressing neuron activity and promoted social interaction in mice [63].

It should also be noted that red-shifted DA variants may be particularly useful in applications where afferent calcium activity needs to be imaged simultaneously. Indeed, although red-shifted calcium sensors are highly effective for imaging local somatic activity, their heightened susceptibility to photobleaching makes them less than an ideal choice for imaging axonal activity. For such situations, green calcium sensors such as axon-GCaMP6f [52] or GCaMP7 [8] are preferred, in combination with red-shifted DA sensors. Moreover, due to their increased light penetration and imaging depth, red-shifted sensors may produce enhanced DA signal quality, which we observed in fiber photometry recordings (see: [59]). This could be an added advantage in applications such as through-cranium imaging applications or to increase maximal imaging depth [237], although this remains to be demonstrated in vivo. 


\subsection{Molecular Scaffold as a Double-Edged Sword for Pharmacology and Drug Discovery}

As outlined above, DA biosensors were generated using DRD1 (dLight1.1, 1.2 and 1.3a, 1.3b, YdLight1, RdLight1), DRD2 (dLight1.5 and all GRAB-DA sensors) or DRD4 (dLight1.4) as the molecular scaffold [58-61,101]. As a result, DA biosensors are sensitive to ligands that target their parent receptor. For instance, in vitro, we found that the dLight1.1 (=DRD1-scaffold) fluorescent response to DA was abolished by the DRD1 antagonists SKF-83566 and SCH-233990 but was unaffected by the DRD2 antagonists haloperidol and sulpiride [58]. In the absence of DA, the RdLight1 (= DRD1 scaffold) fluorescent response increased in response to the DRD1 agonist A77636 and was abolished by SCH-233990. Conversely, in the same assay, dLight1.5 (=DRD2 scaffold) fluorescence increased in response to the DRD2 agonist quinpirole and was abolished by the DRD2 antagonist sulpiride (Figure 6) [59]. Similarly, fluorescent responses to DA were abolished following application of the DRD2 antagonists haloperidol for all GRAB-DA sensors (=DRD2 scaffold) [60,61]. Some of these effects were confirmed at the in vivo level in mice: for instance, we found that optogenetically-evoked dLight1.1 fluorescence was blunted following ip injection of the DRD1 antagonist SCH-233990 [58] (Figure 6). Optogenetically-evoked GRAB-DA responses were also abolished following ip injection of the DRD2 antagonist eticlopride [60,61] (Figure 6). Thus, these findings indicate that DA biosensors appear to reflect the pharmacological properties of the parent DA receptors (i.e., DRD1 or DRD2) from which they were engineered. In effect, this is a double-edged sword for the end-user.

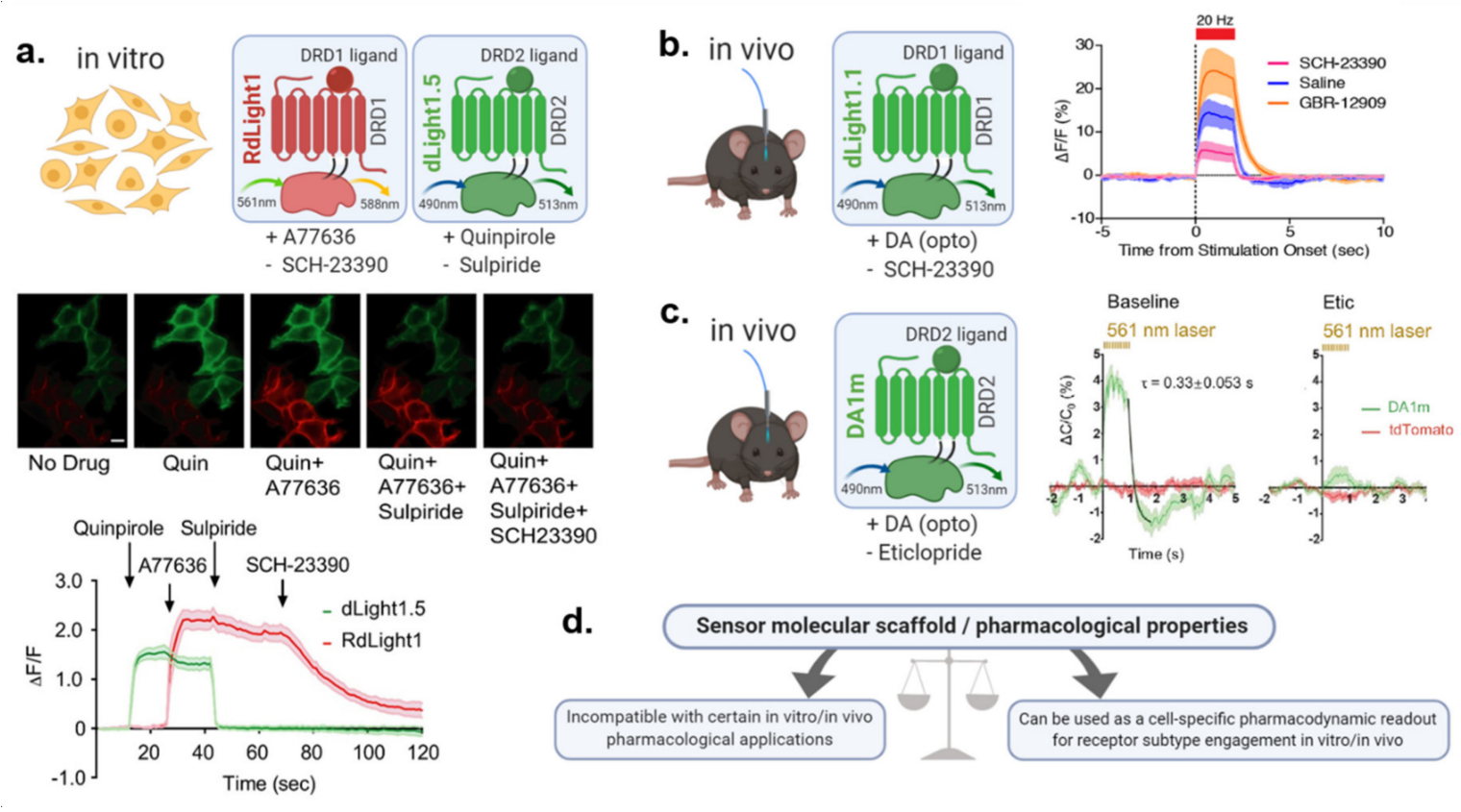

Figure 6. Molecular scaffold as a double-edged sword for pharmacology and drug discovery: (a) In vitro assays: [Top]: multiplex imaging of drug efficacy at distinct dopamine (DA) receptor subtypes in HEK293 cells expressing either RdLight1 (= DRD1 scaffold) or dLight1.5 (= DRD2 scaffold) in the same culture dish. [Middle]: representative images of HEK293 cells and their average fluorescent responses (dFF) to individual drugs. Scale bars, $10 \mu \mathrm{m}$. [Bottom]: Simultaneously measured fluorescence responses of both sensors during bath application of DRD1 drugs: A77636: $100 \mathrm{nM}, \mathrm{SCH} 23390$ : $10 \mu \mathrm{M}$ and DRD2 drugs: Quinpirole (Quin): $10 \mu \mathrm{M}$, Sulpiride: $400 \mathrm{nM}$ [59]. (b,c) In vivo assays: photometry imaging of drug efficacy at DRD1 (b) and DRD2 (c) receptors in mice expressing dLight1.1 (= DRD1 scaffold) or GRAB-DA1m (= DRD2 scaffold) in the NAc or striatum following optogenetic (opto) stimulation of DA neurons in the midbrain and i.p. injection of drugs: SCH23390: 0.25 mg/kg, Eticlopride: $2 \mathrm{mg} / \mathrm{kg}$ (figures were reused with permission from References [58,60]). (d) Pharmacological properties of sensors as a result of their parent receptor scaffold as a double-edged sword. Etic: Eticlopride. "+": agonists, "-“: antagonists. GBR-12909: DA reuptake inhibitor. 
On the one hand, this indicates that DA biosensors may be incompatible with certain in-vitro/in-vivo applications. End-users using DA biosensors as part of pharmacological, drug discovery or drug addiction research must carefully evaluate the affinity of their drug(s) of interest for the sensors. Full agonists/antagonists of DRD1/DRD2 will be of great concern but drugs such as DREADD agonists (e.g., clozapine, CNO [238,239]) or ketamine [240] also have medium to low affinity for DRD1 and/or DRD2, which may in turn affect fluorescent signals. If in doubt, the affinity of a drug for a given biosensor can be determined empirically in HEK293 cells using concentration-response curves, as shown in Figure 4 or otherwise in vivo as shown in Figure 6. An alternative plan is to use FSCV, a method which demonstrates lower cellular and molecular specificity but similar spatiotemporal resolution and which remains unaffected by DA ligands (see Section 2.1). Developing DA sensors with decreased affinity for DRD1/DRD2 ligands is an area of great interest.

On the other hand, the pharmacological profiles of DA biosensors may represent an opportunity to develop novel fluorescent assays for GPCR drug discovery. In vitro, ligand binding fluorescent assays could be developed using concentration-response curves, allowing to determine the relative affinity of a panel of drugs for one or several receptor subtypes. For instance, we showed that spectrally-orthogonal DRD1- (red) and DRD2-based (green) sensors can be expressed simultaneously to examine target engagement of DRD1 vs. DRD2 drugs (Figure 6) [59]. A similar principle can be applied to other neuromodulators by combining, for instance a green NE sensor (nLight1.3) and a red DA sensor (RdLight1) to screen DA/NE candidate ligands [59]. Moreover, these in vitro findings suggest that similar assays could be deployed in vivo, whereby red or green DA biosensors could be used separately or in combination to probe pharmacodynamic target engagement of receptor subtypes. In the future, this could represent an exciting in vivo functional assay for drug development, akin to PET imaging, that would harbor high spatiotemporal resolution, cell specificity and ability to perform screening in awake behaving animals. Future studies are warranted, however, to develop a broader palette of receptor subtype sensors with high specificity (e.g., DRD3, DRD4) and across a wider color palette.

\section{Piloting Sensor Use in the Laboratory}

\subsection{Sensor Validation at the Neuroanatomical Level}

To establish the best sensor for a new brain region, we recommend performing four simple pilot experiments (Figure 7); further experimental details can be found in our extended protocol [99]. First, the optimal construct parameters should be carefully chosen to allow good sensor expression in the cell/region of interest (Figure 7a). Parameters include AAV serotype (1 to 9 or DJ), AAV volume, AAV titer (high titer may lead to cell death) and promoter (e.g., CAG, hSyn, hEF1a, CBA). Often this will match parameters already used in the laboratory to express other molecules of interest. For instance, injection of $150 \mathrm{~nL}$ of an AAV9 expressing dLight1 under CAG or Syn promoter at $1 \times 10^{11}$ viral genomes per milliliter $(\mathrm{VG} / \mathrm{mL})$ into the striatum and 2 weeks incubation time led to expression levels adequate for in vivo imaging with acceptable dFF values $(\sim 10-20 \%)$ for spontaneous peaks [99]. These values may vary from region to region, sensor to sensor or according to the in vitro or in vivo imaging modality (see Reference [99]). If prolonged imaging is required, for example, beyond 2 months, it is important to verify both the GPCR sensor expression levels and the health of the expressing cells. The latter can be performed for example by staining for DAPI to look at neuron numbers, neuroinflammatory markers like GFAP or cell death markers like caspase-3. Other possible validations may include examining cell firing properties in a slice electrophysiology preparation or evaluating the performance of sensor-expressing animals vs. control mice in a behavioral task. 
a. Neuroanatomy validations:



c. In vivo validations: pharmacology



b. In vivo validations: optogenetics



d. In vivo validations: behavior stimuli

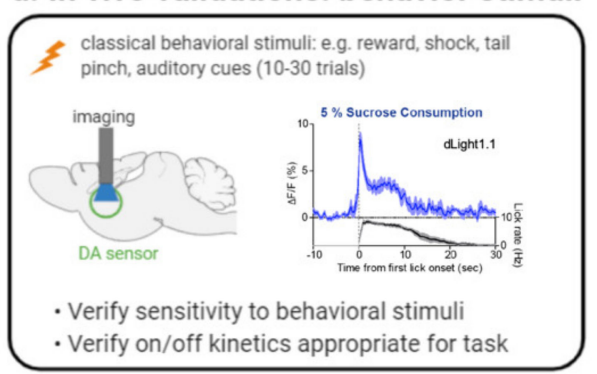

Figure 7. Piloting sensor use in the laboratory can follow these four steps: (a) First, optimal sensor expression in the region or cell of interest should be achieved by optimizing viral injections parameters, often based on protocols previously established in the laboratory for other viral vectors. After a minimum of 2 weeks of incubation, sensor expression can be evaluated as shown here for dLight1.1 in the nucleus accumbens (NAc) [58]. If experiments are expected to last more than 2 months, additional tests can be performed to verify that sensor expression does not induce cell death (e.g., caspase-3 staining) or inflammation (e.g., staining for reactive microglia or astrocyte markers), nor does it affect the basal properties of the cells of interest (membrane potential can be measured in slice physiology). (b) When piloting sensor use in a new brain region with possible sparse innervation, maximal sensor responses should be determined using optogenetic stimulation of dopamine (DA) neurons (e.g., measure NAc DA release using dLight1.1 after ventral tegmental area (VTA) DA neuron ChrimsonR stimulation [58], as shown here). Imaging of DA sensors should be performed using the imaging modality of choice and in vivo kinetics specific for this brain ROI determined by stimulating DA neurons at increasing frequencies (e.g., 5-20 Hz). (c) Pharmacological ligands can be used to validate DA sensors in vivo, e.g., (i) by using reuptake inhibitors e.g., GBR-12909 to increase release or (ii) by using DA receptor antagonists specific to the sensor's parent receptor to decrease [58] (shown here) or abolish (see Reference [226]) fluorescent signals and verify that transients reflect DA release, e.g., using the DRD1 antagonist SCH-23390. (d) In a last step, sensors can be validated using classical behavioral events known to induce DA release in order to verify optimal detection of DA transients in response to physiological stimuli (e.g., measure dLight1.1 responses in the NAc after free sucrose consumption [58], as shown here). Note that native transients will be several-fold lower than after optogenetic stimulations, see Reference [58]). Users should also verify that sensor on/off- kinetics are compatible with the behavioral task of choice. Further information can be found in Reference [99].

\subsection{Sensor Validation In Vivo Using Optogenetic Stimulation}

In a second step, we recommend piloting sensor responses using optogenetic stimulation of afferent DA projections (e.g., of the VTA or SNc cell bodies), which will lead to maximal dFF responses and will allow to establish feasibility (Figure $7 \mathrm{~b}$ ). This can also allow to test the kinetics of the DA sensor, that is, at which maximal stimulation frequency can individual spikes be parsed out and what is the decay time in the brain region of interest. For instance, we found that in the NAc, dLight1.1 reliably tracks individual DA release events following VTA optogenetic stimulation of cell bodies up to $10 \mathrm{~Hz}$ [58]. Note that optogenetic stimulation and imaging can be done through different fibers [58] (Figure 7b) or through the same fiber or lens, as recently shown in Reference [226]. Optogenetic pilots should ideally be done in vivo to closely mimic the experimental conditions of the behavioral 
experiments. However, ex vivo slice experiments may also provide a useful tool to pilot multiple DA sensors at once and to screen sensor properties such as frequency dependency and sensitivity to DA ligands, as we have done previously [58]. In addition, if there is concern for strong NE innervation to the brain region, it may be useful to determine whether DA sensors in the brain region of interest are sensitive either to NE optogenetic stimulation or at least to drugs known to modulate NE release (as in Reference [61]) (note: it may be difficult to parse out indirect circuit effects).

\subsection{Sensor Validation In Vivo Using Pharmacology}

Pharmacological ligands can also be used to validate DA sensors in vivo. On the one hand, reuptake inhibitors such as GBR-12909 can be used to increase release and verify sensitivity of the sensor to pharmacologically-induced modulation of release. For instance, we found that injection of $10 \mathrm{mg} / \mathrm{kg}$ GBR-12909 led to an increase in optogenetically-evoked DA release in the NAc [58]. Moreover, pharmacological antagonists specific to the sensor's parent receptor (e.g., a DRD1 antagonist for the DRD1-based sensors dLight1.1, see Section 5.6) can be used to confirm that detected transients reflect DA release and not movement artefacts or electrical noise. For instance, injection of the DRD1 antagonist SCH-23390 at $0.25 \mathrm{mg} / \mathrm{kg}$ led to a reduction in NAc dLight1.1 fluorescent signal [58] while $10 \mathrm{mg} / \mathrm{kg}$ fully abolished it [226] (Figure 7c).

\subsection{Sensor Validation In Vivo Using Behavioral Stimulation}

In a last step, we recommend testing sensor responses using physiological stimulation such as behavioral stimuli known to affect DA release in the brain region of interest (Figure 7d). Detected transients can be several fold lower than after optogenetic stimulations, as shown in Reference [57] (see also Figure 1 and Section 4.3). For instance, sucrose rewards, reward-predicting auditory cues, electric shocks or aversive bitter solutions rapidly increase or decrease DA release in the NAc [58,60,102], dorsal raphe and central nucleus of the amygdala [38]; acute auditory stimuli like door-opening [113] increase DA release in the dorsal striatum, while tail pinches [23] and footshocks [98] elicit DA release in the mPFC. Use of trial repetitions (e.g., at least 10-30 presentations of the same stimuli) is particularly advantageous, because trial averaging allows even small or variable signals to be reliably detected. Moreover, kinetics should always be considered in relation to the behavioral task of interest. For example, we found that the $\mathrm{t}_{1 / 2}$ decay time of dLight 1.1 sensor to be $100 \mathrm{~ms}$ but other sensors are slower (See Table 1). Thus, it is important to ensure that the intertrial interval (or time between two behavioral stimuli) is substantially higher than the $t_{1 / 2}$ decay time to allow distinguishing responses to subsequent stimuli (see Section 5.3 for further details). Once the data has been collected, it can be analyzed similar to other sensors such as GCaMP.Detailed advice for data analysis can be found in other relevant publications $[62,63,99,241,242]$.

\section{Conclusions}

Here we outlined the large palette of methods that currently exist to measure DA release, focusing a large part of our work on the recently developed DA biosensors, their advantages and limitations as well as their properties. We provided a detailed map of DA regional heterogeneity and argue that local brain DA levels should be accounted for when choosing a sensor based on its affinity. We then provide detailed guidelines for the end-user to optimize sensor choice according to other key sensor properties and experimental modalities. In studies that have already made use of DA biosensors, investigations have thus far primarily focused on the striatum and NAc, two regions with dense DA innervation. We are hopeful that the broad palette of sensors available and expected future developments in the field, will soon allow end-users to address the spatiotemporal dynamics of DA release during behavior in brain regions previously deemed inaccessible with classical methods. It is to be expected that further improvements in ligand affinities to the sensors as well as improvements in the dynamic range will significantly contribute to achieving this goal. Moreover, the more recently developed red-shifted DA sensor RdLight1 opens new doors to decipher neuromodulator dynamics in concert 
with multiple experimental modalities including optogenetic manipulations, multiplex imaging or two-color pharmacological drug screening. Future engineering efforts are expected to allow even more signals to be monitored simultaneously with enhanced sensitivity and specificity and across even broader imaging modalities. The modification of existing GPCR-based DA sensors could for example lead to the development of biosensors compatible with fluorescence life-time imaging, leading to the exciting possibility of measuring absolute DA concentrations in vivo in real-time (reviewed in Reference [118]).

Supplementary Materials: The following are available online at http://www.mdpi.com/1422-0067/21/21/8048/s1, Table S1: Microdialysis, Table S2: DA Sensor Applications.

Author Contributions: Conceptualization, M.A.L., R.B.C. and T.P.; DA brain maps, R.B.C.; Other figures: M.A.L.; writing, M.A.L., R.B.C. and T.P.; funding acquisition, M.A.L., R.B.C. and T.P. All authors have read and agreed to the published version of the manuscript.

Funding: This review was made possible by funding from the Swiss National Science Foundation, grants number P400PB_180841 and P4P4PB_191069 (to M.A.L.) as well as the University of Zurich and the Olga Mayenfisch foundation (funding to T.P.).

Acknowledgments: The authors thank Christoph Kellendonk (Columbia University) and Marco R. Celio (University of Fribourg) for infrastructural and/or scientific support. Figures were created with Biorender.

Conflicts of Interest: The authors declare no conflict of interest.

\section{Abbreviations}

$\begin{array}{ll}\text { AAV } & \text { Adeno-associated virus } \\ \text { Amy } & \text { Amygdala } \\ \text { AP } & \text { Action potential } \\ \text { Au1 } & \text { Primary auditory cortex } \\ \text { BNST } & \text { Bed nucleus of the stria terminalis } \\ \text { CAG } & \text { Human cytomegalovirus promoter } \\ \text { cAMP } & \text { Cyclic adenosine monophosphate } \\ \text { CNiFERs } & \text { Cell-based neurotransmitter fluorescent engineered reporters } \\ \text { CNO } & \text { Clozapine-N-oxide } \\ \text { cpFP } & \text { Circularly-permuted fluorescent protein } \\ \text { cpGFP } & \text { Circularly-permuted green fluorescent protein } \\ \text { cpmApple } & \text { Circularly-permuted mApple (fluorescent protein) } \\ \text { CPu } & \text { Caudate-Putamen (= striatum) } \\ \text { CRB } & \text { Cerebellum } \\ \text { DA } & \text { Dopamine } \\ \text { dFF } & \text { Normalized fluorescent response ( } \Delta \text { F/F) } \\ \text { DR } & \text { Dorsal raphe nuclei } \\ \text { DRD1-5 } & \text { Genes encoding D1-D5 dopamine receptors } \\ \text { EC50 } & \text { Half maximal effective concentration } \\ \text { Emis } & \text { Emission wavelength } \\ \text { ENT } & \text { Enthorhinal cortex } \\ \text { Exc } & \text { Excitation wavelength } \\ \text { FFNs } & \text { False fluorescent neurotransmitters } \\ \text { FRET } & \text { Förster resonance energy transfer } \\ \text { FSCV } & \text { Fast-scan cyclic voltammetry } \\ \text { GECIs } & \text { Genetically-encoded calcium indicators } \\ \text { GFAP } & \text { Glial fibrillary acidic protein } \\ \text { GPCR } & \text { G protein-coupled receptor }\end{array}$




$\begin{array}{ll}\text { GPe } & \text { Globus pallidus externus } \\ \text { GRAB } & \text { GPCR-activation based sensors } \\ \text { GTP } & \text { Guanosine triphosphate } \\ \text { HEK-293 } & \text { Human embryonic kidney cell line } \\ \text { HPC } & \text { Hippocampal formation } \\ \text { HPLC } & \text { High-performance liquid chromatography } \\ \text { hSyn } & \text { Human synapsin promoter } \\ \text { Hyp } & \text { Hypothalamus } \\ \text { Kd } & \text { Dissociation constant } \\ \text { LS } & \text { Lateral septum } \\ \text { M1 } & \text { Primary motor cortex } \\ \text { M2 } & \text { Secondary motor cortex } \\ \text { mPFC } & \text { Medial prefrontal cortex } \\ \text { MS } & \text { Medial septum } \\ \text { NAc } & \text { Nucleus accumbens } \\ \text { ND } & \text { Not determined } \\ \text { NE } & \text { Norepinephrine } \\ \text { OT } & \text { Olfactory tubercle } \\ \text { PBP } & \text { Periplasmic Binding Protein } \\ \text { PVT } & \text { Paraventricular thalamus } \\ \text { ROI } & \text { Region of Interest } \\ \text { SN } & \text { Substantia nigra } \\ \text { SNc } & \text { Subtantia nigra pars compacta } \\ \text { SNR } & \text { Signal-to-noise ratio } \\ \text { SWCNT } & \text { Single-walled carbon nanotubes } \\ \text { TeA } & \text { Temporal association cortex } \\ \text { TEV } & \text { Tobacco Etch Virus peptide sequence } \\ \text { TIRF } & \text { Total internal reflection microscopy } \\ \text { TRE } & \text { Tetracycline response element } \\ \text { tTA } & \text { Tetracycline-controlled transactivator } \\ \text { VP } & \text { Ventral pallidum } \\ \text { VMAT2 } & \text { Vesicular monoamine transporter 2 } \\ \text { VTA } & \end{array}$

\section{References}

1. Bargmann, C.I. Beyond the connectome: How neuromodulators shape neural circuits. BioEssays 2012, 34, 458-465. [CrossRef]

2. Marder, E. Neuromodulation of neuronal circuits: Back to the future. Neuron 2012, 76, 1-11. [CrossRef] [PubMed]

3. Picciotto, M.R.; Higley, M.J.; Mineur, Y.S. Acetylcholine as a Neuromodulator: Cholinergic Signaling Shapes Nervous System Function and Behavior. Neuron 2012, 76, 116-129. [CrossRef] [PubMed]

4. Tritsch, N.X.; Sabatini, B.L. Dopaminergic modulation of synaptic transmission in cortex and striatum. Neuron 2012, 76, 33-50. [CrossRef] [PubMed]

5. Miyawaki, A.; Llopis, J.; Heim, R.; McCaffery, J.M.; Adams, J.A.; Ikura, M.; Tsien, R.Y. Fluorescent indicators for $\mathrm{Ca} 2+$ based on green fluorescent proteins and calmodulin. Nature 1997, 388, 882-887. [CrossRef] [PubMed]

6. Akerboom, J.; Chen, T.-W.; Wardill, T.J.; Tian, L.; Marvin, J.S.; Mutlu, S.; Calderon, N.C.; Esposti, F.; Borghuis, B.G.; Sun, X.R.; et al. Optimization of a GCaMP Calcium Indicator for Neural Activity Imaging. J. Neurosci. 2012, 32, 13819-13840. [CrossRef]

7. Chen, T.-W.; Wardill, T.J.; Sun, Y.; Pulver, S.R.; Renninger, S.L.; Baohan, A.; Schreiter, E.R.; Kerr, R.A.; Orger, M.B.; Jayaraman, V.; et al. Ultrasensitive fluorescent proteins for imaging neuronal activity. Nature 2013, 499, 295-300. [CrossRef] 
8. Dana, H.; Sun, Y.; Mohar, B.; Hulse, B.K.; Kerlin, A.M.; Hasseman, J.P.; Tsegaye, G.; Tsang, A.; Wong, A.; Patel, R.; et al. High-performance calcium sensors for imaging activity in neuronal populations and microcompartments. Nat. Methods 2019, 16, 649-657. [CrossRef]

9. Tian, L.; Hires, S.A.; Mao, T.; Huber, D.; Chiappe, M.E.; Chalasani, S.H.; Petreanu, L.; Akerboom, J.; McKinney, S.A.; Schreiter, E.R.; et al. Imaging neural activity in worms, flies and mice with improved GCaMP calcium indicators. Nat. Methods 2009, 6, 875-881. [CrossRef]

10. Colgan, L.A.; Cavolo, S.L.; Commons, K.G.; Levitan, E.S. Action Potential-Independent and Pharmacologically Unique Vesicular Serotonin Release from Dendrites. J. Neurosci. 2012, 32, 15737-15746. [CrossRef]

11. Sulzer, D.; Cragg, S.J.; Rice, M.E. Striatal dopamine neurotransmission: Regulation of release and uptake. Basal Ganglia 2016, 6, 123-148. [CrossRef] [PubMed]

12. Nadim, F.; Bucher, D. Neuromodulation of Neurons and Synapses. Curr. Opin. Neurobiol. 2014, $29,48-56$. [CrossRef] [PubMed]

13. Rusakov, D.A.; Savtchenko, L.P.; Zheng, K.; Henley, J.M. Shaping the synaptic signal: Molecular mobility inside and outside the cleft. Trends Neurosci. 2011, 34, 359-369. [CrossRef] [PubMed]

14. Gerfen, C.R.; Surmeier, D.J. Modulation of striatal projection systems by dopamine. Annu. Rev. Neurosci. 2011, 34, 441-466. [CrossRef]

15. Berridge, K.C. The debate over dopamine's role in reward: The case for incentive salience. Psychopharmacology 2007, 191, 391-431. [CrossRef]

16. Salamone, J.D.; Correa, M.; Yang, J.-H.; Rotolo, R.; Presby, R. Dopamine, Effort-Based Choice, and Behavioral Economics: Basic and Translational Research. Front. Behav. Neurosci. 2018, 12, 52. [CrossRef]

17. Bromberg-Martin, E.S.; Matsumoto, M.; Hikosaka, O. Dopamine in motivational control: Rewarding, aversive, and alerting. Neuron 2010, 68, 815-834. [CrossRef]

18. Berke, J.D. What does dopamine mean? Nat. Neurosci. 2018, 21, 787-793. [CrossRef]

19. Costa, R.M. Plastic corticostriatal circuits for action learning: What's dopamine got to do with it? Ann. N. Y. Acad. Sci. 2007, 1104, 172-191. [CrossRef]

20. Klaus, A.; Alves da Silva, J.; Costa, R.M. What, If, and When to Move: Basal Ganglia Circuits and Self-Paced Action Initiation. Annu. Rev. Neurosci. 2019, 42, 459-483. [CrossRef]

21. Goldman-Rakic, P.S. The cortical dopamine system: Role in memory and cognition. Adv. Pharmacol. 1998, 42, 707-711. [CrossRef] [PubMed]

22. Ott, T.; Nieder, A. Dopamine and Cognitive Control in Prefrontal Cortex. Trends Cogn. Sci. (Regul. Ed.) 2019, 23, 213-234. [CrossRef]

23. Vander Weele, C.M.; Siciliano, C.A.; Matthews, G.A.; Namburi, P.; Izadmehr, E.M.; Espinel, I.C.; Nieh, E.H.; Schut, E.H.S.; Padilla-Coreano, N.; Burgos-Robles, A.; et al. Dopamine enhances signal-to-noise ratio in cortical-brainstem encoding of aversive stimuli. Nature 2018, 563, 397-401. [CrossRef] [PubMed]

24. Matthews, G.A.; Nieh, E.H.; Vander Weele, C.M.; Halbert, S.A.; Pradhan, R.V.; Yosafat, A.S.; Glober, G.F.; Izadmehr, E.M.; Thomas, R.E.; Lacy, G.D.; et al. Dorsal Raphe Dopamine Neurons Represent the Experience of Social Isolation. Cell 2016, 164, 617-631. [CrossRef]

25. Kenny, P.J.; Voren, G.; Johnson, P.M. Dopamine D2 receptors and striatopallidal transmission in addiction and obesity. Curr. Opin. Neurobiol. 2013, 23, 535-538. [CrossRef]

26. Han, W.; Tellez, L.A.; Perkins, M.H.; Perez, I.O.; Qu, T.; Ferreira, J.; Ferreira, T.L.; Quinn, D.; Liu, Z.-W.; Gao, X.-B.; et al. A Neural Circuit for Gut-Induced Reward. Cell 2018, 175, 665-678. [CrossRef] [PubMed]

27. Berland, C.; Montalban, E.; Perrin, E.; Di Miceli, M.; Nakamura, Y.; Martinat, M.; Sullivan, M.; Davis, X.S.; Shenasa, M.A.; Martin, C.; et al. Circulating Triglycerides Gate Dopamine-Associated Behaviors through DRD2-Expressing Neurons. Cell Metab. 2020, 31, 773-790. [CrossRef] [PubMed]

28. Fernandes, A.B.; Alves da Silva, J.; Almeida, J.; Cui, G.; Gerfen, C.R.; Costa, R.M.; Oliveira-Maia, A.J. Postingestive Modulation of Food Seeking Depends on Vagus-Mediated Dopamine Neuron Activity. Neuron 2020. [CrossRef] [PubMed]

29. Beeler, J.A.; Faust, R.P.; Turkson, S.; Ye, H.; Zhuang, X. Low Dopamine D2 Receptor Increases Vulnerability to Obesity Via Reduced Physical Activity, Not Increased Appetitive Motivation. Biol. Psychiatry 2016, 79, 887-897. [CrossRef] [PubMed]

30. Friend, D.M.; Devarakonda, K.; O’Neal, T.J.; Skirzewski, M.; Papazoglou, I.; Kaplan, A.R.; Liow, J.-S.; Guo, J.; Rane, S.G.; Rubinstein, M.; et al. Basal Ganglia Dysfunction Contributes to Physical Inactivity in Obesity. Cell Metab. 2017, 25, 312-321. [CrossRef] 
31. Welch, A.C.; Zhang, J.; Lyu, J.; McMurray, M.S.; Javitch, J.A.; Kellendonk, C.; Dulawa, S.C. Dopamine D2 receptor overexpression in the nucleus accumbens core induces robust weight loss during scheduled fasting selectively in female mice. Mol. Psychiatry 2019. [CrossRef] [PubMed]

32. Labouesse, M.A.; Sartori, A.M.; Weinmann, O.; Simpson, E.H.; Kellendonk, C.; Weber-Stadlbauer, U. Striatal dopamine 2 receptor upregulation during development predisposes to diet-induced obesity by reducing energy output in mice. Proc. Natl. Acad. Sci. USA 2018, 115, 10493-10498. [CrossRef]

33. Folgueira, C.; Beiroa, D.; Porteiro, B.; Duquenne, M.; Puighermanal, E.; Fondevila, M.F.; Barja-Fernández, S.; Gallego, R.; Hernández-Bautista, R.; Castelao, C.; et al. Hypothalamic dopamine signalling regulates brown fat thermogenesis. Nat. Metab. 2019, 1, 811-829. [CrossRef] [PubMed]

34. Fitzgerald, P.; Dinan, T.G. Prolactin and dopamine: What is the connection? A review article. J. Psychopharmacol. (Oxf.) 2008, 22, 12-19. [CrossRef]

35. Björklund, A.; Dunnett, S.B. Dopamine neuron systems in the brain: An update. Trends Neurosci. 2007, 30, 194-202. [CrossRef] [PubMed]

36. Dahlstroem, A.; Fuxe, K. Evidence for the existence of monoamine-containing neurons in the central nervous system. I. Demonstration of monoamines in the cell bodies of brain stem neurons. Acta Physiol. Scand. Suppl. 1964, 62 (Suppl. 232), 1-55.

37. Lyons, D.J.; Hellysaz, A.; Broberger, C. Prolactin Regulates Tuberoinfundibular Dopamine Neuron Discharge Pattern: Novel Feedback Control Mechanisms in the Lactotrophic Axis. J. Neurosci. 2012, 32, 8074-8083. [CrossRef]

38. Lin, R.; Liang, J.; Wang, R.; Yan, T.; Zhou, Y.; Liu, Y.; Feng, Q.; Sun, F.; Li, Y.; Li, A.; et al. The Raphe Dopamine System Controls the Expression of Incentive Memory. Neuron 2020, 106, 498-514. [CrossRef]

39. Beas, B.S.; Wright, B.J.; Skirzewski, M.; Leng, Y.; Hyun, J.H.; Koita, O.; Ringelberg, N.; Kwon, H.-B.; Buonanno, A.; Penzo, M.A. The locus coeruleus drives disinhibition in the midline thalamus via a dopaminergic mechanism. Nat. Neurosci. 2018, 21, 963-973. [CrossRef]

40. Kempadoo, K.A.; Mosharov, E.V.; Choi, S.J.; Sulzer, D.; Kandel, E.R. Dopamine release from the locus coeruleus to the dorsal hippocampus promotes spatial learning and memory. Proc. Natl. Acad. Sci. USA 2016, 113, 14835-14840. [CrossRef]

41. Rice, M.E.; Patel, J.C. Somatodendritic dopamine release: Recent mechanistic insights. Philos Trans. R. Soc. Lond. B. Biol. Sci. 2015, 370. [CrossRef] [PubMed]

42. Adams, B.W.; Moghaddam, B. Tactile stimulation activates dopamine release in the lateral septum. Brain Res. 2000, 858, 177-180. [CrossRef]

43. Clark, M.; Bracci, E. Dichotomous Dopaminergic Control of Ventral Pallidum Neurons. Front. Cell Neurosci. 2018, 12. [CrossRef] [PubMed]

44. Meszaros, J.; Cheung, T.; Erler, M.M.; Kang, U.J.; Sames, D.; Kellendonk, C.; Sulzer, D. Evoked transients of $\mathrm{pH}$-sensitive fluorescent false neurotransmitter reveal dopamine hot spots in the globus pallidus. eLife 2018, 7, e42383. [CrossRef] [PubMed]

45. Aransay, A.; RodrÃguez-LÃ3pez, C.; GarcÃa-Amado, M.; ClascÃ $i$, F.; Prensa, L. Long-range projection neurons of the mouse ventral tegmental area: A single-cell axon tracing analysis. Front. Neuroanat. 2015, 9. [CrossRef]

46. Lindvall, O.; Björklund, A. The glyoxylic acid fluorescence histochemical method: A detailed account of the methodology for the visualization of central catecholamine neurons. Histochemistry 1974, 39, 97-127. [CrossRef]

47. Jones, S.R.; Mickelson, G.E.; Collins, L.B.; Kawagoe, K.T.; Wightman, R.M. Interference by pH and Ca2+ ions during measurements of catecholamine release in slices of rat amygdala with fast-scan cyclic voltammetry. J. Neurosci. Methods 1994, 52, 1-10. [CrossRef]

48. Koch, S.; Perry, K.W.; Nelson, D.L.; Conway, R.G.; Threlkeld, P.G.; Bymaster, F.P. R-fluoxetine Increases Extracellular DA, NE, As Well As 5-HT in Rat Prefrontal Cortex and Hypothalamus: An in vivo Microdialysis and Receptor Binding Study. Neuropsychopharmacology 2002, 27, 949-959. [CrossRef]

49. Muller, A.; Joseph, V.; Slesinger, P.A.; Kleinfeld, D. Cell-based reporters reveal in vivo dynamics of dopamine and norepinephrine release in murine cortex. Nat. Methods 2014, 11, 1245-1252. [CrossRef]

50. Kim, M.W.; Wang, W.; Sanchez, M.I.; Coukos, R.; von Zastrow, M.; Ting, A.Y. Time-gated detection of protein-protein interactions with transcriptional readout. Elife 2017, 6. [CrossRef] 
51. Lee, D.; Creed, M.; Jung, K.; Stefanelli, T.; Wendler, D.J.; Oh, W.C.; Mignocchi, N.L.; Lüscher, C.; Kwon, H.-B. Temporally precise labeling and control of neuromodulatory circuits in the mammalian brain. Nat. Methods 2017, 14, 495-503. [CrossRef]

52. Broussard, G.J.; Liang, Y.; Fridman, M.; Unger, E.K.; Meng, G.; Xiao, X.; Ji, N.; Petreanu, L.; Tian, L. In vivo measurement of afferent activity with axon-specific calcium imaging. Nat. Neurosci. 2018, 21, 1272-1280. [CrossRef] [PubMed]

53. Mahn, M.; Prigge, M.; Ron, S.; Levy, R.; Yizhar, O. Biophysical constraints of optogenetic inhibition at presynaptic terminals. Nat. Neurosci. 2016, 19, 554-556. [CrossRef]

54. Howe, M.W.; Dombeck, D.A. Rapid signalling in distinct dopaminergic axons during locomotion and reward. Nature 2016, 535, 505-510. [CrossRef] [PubMed]

55. Parker, N.F.; Cameron, C.M.; Taliaferro, J.P.; Lee, J.; Choi, J.Y.; Davidson, T.J.; Daw, N.D.; Witten, I.B. Reward and choice encoding in terminals of midbrain dopamine neurons depends on striatal target. Nat. Neurosci. 2016, 19, 845-854. [CrossRef] [PubMed]

56. Gubernator, N.G.; Zhang, H.; Staal, R.G.W.; Mosharov, E.V.; Pereira, D.B.; Yue, M.; Balsanek, V.; Vadola, P.A.; Mukherjee, B.; Edwards, R.H.; et al. Fluorescent False Neurotransmitters Visualize Dopamine Release from Individual Presynaptic Terminals. Science 2009, 324, 1441-1444. [CrossRef] [PubMed]

57. Beyene, A.G.; Delevich, K.; Del Bonis-O’Donnell, J.T.; Piekarski, D.J.; Lin, W.C.; Thomas, A.W.; Yang, S.J.; Kosillo, P.; Yang, D.; Prounis, G.S.; et al. Imaging striatal dopamine release using a nongenetically encoded near infrared fluorescent catecholamine nanosensor. Sci. Adv. 2019, 5, eaaw3108. [CrossRef]

58. Patriarchi, T.; Cho, J.R.; Merten, K.; Howe, M.W.; Marley, A.; Xiong, W.-H.; Folk, R.W.; Broussard, G.J.; Liang, R.; Jang, M.J.; et al. Ultrafast neuronal imaging of dopamine dynamics with designed genetically encoded sensors. Science 2018, 360, eaat4422. [CrossRef]

59. Patriarchi, T.; Mohebi, A.; Sun, J.; Marley, A.; Liang, R.; Dong, C.; Puhger, K.; Mizuno, G.O.; Davis, C.M.; Wiltgen, B.; et al. An expanded palette of dopamine sensors for multiplex imaging in vivo. Nat. Methods 2020, 1-9. [CrossRef]

60. Sun, F.; Zeng, J.; Jing, M.; Zhou, J.; Feng, J.; Owen, S.F.; Luo, Y.; Li, F.; Wang, H.; Yamaguchi, T.; et al. A Genetically Encoded Fluorescent Sensor Enables Rapid and Specific Detection of Dopamine in Flies, Fish, and Mice. Cell 2018, 174, 481-496. [CrossRef]

61. Sun, F.; Zhou, J.; Dai, B.; Qian, T.; Zeng, J.; Li, X.; Zhuo, Y.; Zhang, Y.; Tan, K.; Feng, J.; et al. New and improved GRAB fluorescent sensors for monitoring dopaminergic activity in vivo. bioRxiv 2020. [CrossRef]

62. Siciliano, C.A.; Tye, K.M. Leveraging calcium imaging to illuminate circuit dysfunction in addiction. Alcohol 2019, 74, 47-63. [CrossRef]

63. Gunaydin, L.A.; Grosenick, L.; Finkelstein, J.C.; Kauvar, I.V.; Fenno, L.E.; Adhikari, A.; Lammel, S.; Mirzabekov, J.J.; Airan, R.D.; Zalocusky, K.A.; et al. Natural Neural Projection Dynamics Underlying Social Behavior. Cell 2014, 157, 1535-1551. [CrossRef]

64. Kim, C.K.; Yang, S.J.; Pichamoorthy, N.; Young, N.P.; Kauvar, I.; Jennings, J.H.; Lerner, T.N.; Berndt, A.; Lee, S.Y.; Ramakrishnan, C.; et al. Simultaneous fast measurement of circuit dynamics at multiple sites across the mammalian brain. Nat. Methods 2016, 13, 325-328. [CrossRef]

65. Sych, Y.; Chernysheva, M.; Sumanovski, L.T.; Helmchen, F. High-density multi-fiber photometry for studying large-scale brain circuit dynamics. Nat. Methods 2019, 16, 553-560. [CrossRef] [PubMed]

66. Helmchen, F.; Fee, M.S.; Tank, D.W.; Denk, W. A Miniature Head-Mounted Two-Photon Microscope: High-Resolution Brain Imaging in Freely Moving Animals. Neuron 2001, 31, 903-912. [CrossRef]

67. Flusberg, B.A.; Nimmerjahn, A.; Cocker, E.D.; Mukamel, E.A.; Barretto, R.P.J.; Ko, T.H.; Burns, L.D.; Jung, J.C.; Schnitzer, M.J. High-speed, miniaturized fluorescence microscopy in freely moving mice. Nat. Methods 2008, 5, 935-938. [CrossRef] [PubMed]

68. Kim, T.H.; Zhang, Y.; Lecoq, J.; Jung, J.C.; Li, J.; Zeng, H.; Niell, C.M.; Schnitzer, M.J. Long-Term Optical Access to an Estimated One Million Neurons in the Live Mouse Cortex. Cell Rep. 2016, 17, 3385-3394. [CrossRef]

69. Sofroniew, N.J.; Flickinger, D.; King, J.; Svoboda, K. A large field of view two-photon mesoscope with subcellular resolution for in vivo imaging. Elife 2016, 5. [CrossRef] [PubMed]

70. Beyene, A.G.; Yang, S.J.; Landry, M.P. Review Article: Tools and trends for probing brain neurochemistry. J. Vac. Sci. Technol. A 2019, 37, 040802. [CrossRef] [PubMed] 
71. Oe, Y.; Wang, X.; Patriarchi, T.; Konno, A.; Ozawa, K.; Yahagi, K.; Hirai, H.; Tian, L.; McHugh, T.J.; Hirase, H. Distinct temporal integration of noradrenaline signaling by astrocytic second messengers during vigilance. Nat. Commun. 2020, 11, 471. [CrossRef] [PubMed]

72. Feng, J.; Zhang, C.; Lischinsky, J.E.; Jing, M.; Zhou, J.; Wang, H.; Zhang, Y.; Dong, A.; Wu, Z.; Wu, H.; et al. A Genetically Encoded Fluorescent Sensor for Rapid and Specific In Vivo Detection of Norepinephrine. Neuron 2019, 102, 745-761. [CrossRef] [PubMed]

73. Jing, M.; Zhang, P.; Wang, G.; Feng, J.; Mesik, L.; Zeng, J.; Jiang, H.; Wang, S.; Looby, J.C.; Guagliardo, N.A.; et al. A genetically encoded fluorescent acetylcholine indicator for in vitro and in vivo studies. Nat. Biotechnol. 2018, 36, 726-737. [CrossRef] [PubMed]

74. Jing, M.; Li, Y.; Zeng, J.; Huang, P.; Skirzewski, M.; Kljakic, O.; Peng, W.; Qian, T.; Tan, K.; Zou, J.; et al. An optimized acetylcholine sensor for monitoring in vivo cholinergic activity. Nat. Methods 2020. [CrossRef]

75. Wan, J.; Peng, W.; Li, X.; Qian, T.; Song, K.; Zeng, J.; Deng, F.; Hao, S.; Feng, J.; Zhang, P.; et al. A genetically encoded GRAB sensor for measuring serotonin dynamics in vivo. bioRxiv 2020. [CrossRef]

76. Peng, W.; Wu, Z.; Song, K.; Zhang, S.; Li, Y.; Xu, M. Regulation of sleep homeostasis mediator adenosine by basal forebrain glutamatergic neurons. Science 2020, 369. [CrossRef]

77. Dana, H.; Mohar, B.; Sun, Y.; Narayan, S.; Gordus, A.; Hasseman, J.P.; Tsegaye, G.; Holt, G.T.; Hu, A.; Walpita, D.; et al. Sensitive red protein calcium indicators for imaging neural activity. eLife 2016, 5, e12727. [CrossRef]

78. Justice, J.B. The Evolution of in Vivo Voltammetry and Microdialysis. In Catecholamine Research: From Molecular Insights to Clinical Medicine; Nagatsu, T., Nabeshima, T., McCarty, R., Goldstein, D.S., Eds.; Advances in Behavioral Biology; Springer: Boston, MA, USA, 2002; pp. 301-304, ISBN 978-1-4757-3538-3.

79. Budygin, E.A.; Kilpatrick, M.R.; Gainetdinov, R.R.; Wightman, R.M. Correlation between behavior and extracellular dopamine levels in rat striatum: Comparison of microdialysis and fast-scan cyclic voltammetry. Neurosci. Lett. 2000, 281, 9-12. [CrossRef]

80. Darvesh, A.S.; Carroll, R.T.; Geldenhuys, W.J.; Gudelsky, G.A.; Klein, J.; Meshul, C.K.; Van der Schyf, C.J. In vivo brain microdialysis: Advances in neuropsychopharmacology and drug discovery. Expert Opin. Drug Discov. 2011, 6, 109-127. [CrossRef]

81. Fuchs, H.; Hauber, W. Dopaminergic innervation of the rat globus pallidus characterized by microdialysis and immunohistochemistry. Exp. Brain Res. 2004, 154, 66-75. [CrossRef]

82. Wightman, R.M. Detection technologies. Probing cellular chemistry in biological systems with microelectrodes. Science 2006, 311, 1570-1574. [CrossRef] [PubMed]

83. Zachek, M.K.; Park, J.; Takmakov, P.; Wightman, R.M.; McCarty, G.S. Microfabricated FSCV-compatible microelectrode array for real-time monitoring of heterogeneous dopamine release. Analyst 2010, 135, 1556-1563. [CrossRef]

84. Schwerdt, H.N.; Kim, M.J.; Amemori, S.; Homma, D.; Yoshida, T.; Shimazu, H.; Yerramreddy, H.; Karasan, E.; Langer, R.; Graybiel, A.M.; et al. Subcellular probes for neurochemical recording from multiple brain sites. Lab Chip 2017, 17, 1104-1115. [CrossRef] [PubMed]

85. Briand, L.A.; Gritton, H.; Howe, W.M.; Young, D.A.; Sarter, M. Modulators in concert for cognition: Modulator interactions in the prefrontal cortex. Prog. Neurobiol. 2007, 83, 69-91. [CrossRef] [PubMed]

86. Pereira, D.B.; Schmitz, Y.; Mészáros, J.; Merchant, P.; Hu, G.; Li, S.; Henke, A.; Lizardi-Ortiz, J.E.; Karpowicz, R.J.; Morgenstern, T.J.; et al. Fluorescent false neurotransmitter reveals functionally silent dopamine vesicle clusters in the striatum. Nat. Neurosci. 2016, 19, 578-586. [CrossRef]

87. Dunn, M.; Henke, A.; Clark, S.; Kovalyova, Y.; Kempadoo, K.A.; Karpowicz, R.J.; Kandel, E.R.; Sulzer, D.; Sames, D. Designing a norepinephrine optical tracer for imaging individual noradrenergic synapses and their activity in vivo. Nat. Comm. 2018, 9, 2838. [CrossRef] [PubMed]

88. Kruss, S.; Landry, M.P.; Vander Ende, E.; Lima, B.M.A.; Reuel, N.F.; Zhang, J.; Nelson, J.; Mu, B.; Hilmer, A.; Strano, M. Neurotransmitter Detection Using Corona Phase Molecular Recognition on Fluorescent Single-Walled Carbon Nanotube Sensors. J. Am. Chem. Soc. 2014, 136, 713-724. [CrossRef]

89. Kruss, S.; Salem, D.P.; Vuković, L.; Lima, B.; Ende, E.V.; Boyden, E.S.; Strano, M.S. High-resolution imaging of cellular dopamine efflux using a fluorescent nanosensor array. Proc. Natl. Acad. Sci. USA 2017, 114, 1789-1794. [CrossRef]

90. Dinarvand, M.; Elizarova, S.; Daniel, J.; Kruss, S. Imaging of Monoamine Neurotransmitters with Fluorescent Nanoscale Sensors. ChemPlusChem 2020, 85, 1465-1480. [CrossRef] 
91. Nguyen, Q.-T.; Schroeder, L.F.; Mank, M.; Muller, A.; Taylor, P.; Griesbeck, O.; Kleinfeld, D. An in vivo biosensor for neurotransmitter release and in situ receptor activity. Nat. Neurosci. 2010, 13, 127-132. [CrossRef]

92. Barnea, G.; Strapps, W.; Herrada, G.; Berman, Y.; Ong, J.; Kloss, B.; Axel, R.; Lee, K.J. The genetic design of signaling cascades to record receptor activation. Proc. Natl. Acad. Sci. USA 2008, 105, 64-69. [CrossRef] [PubMed]

93. Inagaki, H.K.; Ben-Tabou de-Leon, S.; Wong, A.M.; Jagadish, S.; Ishimoto, H.; Barnea, G.; Kitamoto, T.; Axel, R.; Anderson, D.J. Visualizing Neuromodulation In Vivo: TANGO-Mapping of Dopamine Signaling Reveals Appetite Control of Sugar Sensing. Cell 2012, 148, 583-595. [CrossRef] [PubMed]

94. Howe, M.; Ridouh, I.; Allegra Mascaro, A.L.; Larios, A.; Azcorra, M.; Dombeck, D.A. Coordination of rapid cholinergic and dopaminergic signaling in striatum during spontaneous movement. eLife 2019, 8, e44903. [CrossRef]

95. Liu, C.; Kaeser, P.S. Mechanisms and regulation of dopamine release. Curr. Opin. Neurobiol. 2019, 57, 46-53. [CrossRef]

96. Ford, C.P. The role of D2-autoreceptors in regulating dopamine neuron activity and transmission. Neuroscience 2014, 282, 13-22. [CrossRef] [PubMed]

97. Sturgill, J.; Hegedus, P.; Li, S.; Chevy, Q.; Siebels, A.; Jing, M.; Li, Y.; Hangya, B.; Kepecs, A. Basal forebrain-derived acetylcholine encodes valence-free reinforcement prediction error. bioRxiv 2020. [CrossRef]

98. Wu, M.; Minkowicz, S.; Dumrongprechachan, V.; Hamilton, P.; Xiao, L.; Kozorovitskiy, Y. Ketamine restores escape behavior by re-engaging dopamine systems to drive cortical spinogenesis. bioRxiv 2020. [CrossRef]

99. Patriarchi, T.; Cho, J.R.; Merten, K.; Marley, A.; Broussard, G.J.; Liang, R.; Williams, J.; Nimmerjahn, A.; von Zastrow, M.; Gradinaru, V.; et al. Imaging neuromodulators with high spatiotemporal resolution using genetically encoded indicators. Nat. Protoc. 2019, 14, 3471-3505. [CrossRef] [PubMed]

100. Nakamoto, C.; Goto, Y.; Tomizawa, Y.; Fukata, Y.; Fukata, M.; Harpsøe, K.; Gloriam, D.E.; Aoki, K.; Takeuchi, T. A genetically encoded red fluorescence dopamine biosensor enables dual imaging of dopamine and norepinephrine. bioRxiv 2020. [CrossRef]

101. Mohebi, A.; Pettibone, J.R.; Hamid, A.A.; Wong, J.-M.T.; Vinson, L.T.; Patriarchi, T.; Tian, L.; Kennedy, R.T.; Berke, J.D. Dissociable dopamine dynamics for learning and motivation. Nature 2019, 570, 65-70. [CrossRef]

102. Yuan, L.; Dou, Y.-N.; Sun, Y.-G. Topography of Reward and Aversion Encoding in the Mesolimbic Dopaminergic System. J. Neurosci. 2019, 39, 6472-6481. [CrossRef]

103. Lutas, A.; Kucukdereli, H.; Alturkistani, O.; Carty, C.; Sugden, A.U.; Fernando, K.; Diaz, V.; Flores-Maldonado, V.; Andermann, M.L. State-specific gating of salient cues by midbrain dopaminergic input to basal amygdala. Nat. Neurosci. 2019, 22, 1820-1833. [CrossRef] [PubMed]

104. Iino, Y.; Sawada, T.; Yamaguchi, K.; Tajiri, M.; Ishii, S.; Kasai, H.; Yagishita, S. Dopamine D2 receptors in discrimination learning and spine enlargement. Nature 2020, 579, 555-560. [CrossRef] [PubMed]

105. Kim, H.R.; Malik, A.N.; Mikhael, J.G.; Bech, P.; Tsutsui-Kimura, I.; Sun, F.; Zhang, Y.; Li, Y.; Watabe-Uchida, M.; Gershman, S.J.; et al. A unified framework for dopamine signals across timescales. bioRxiv 2019, 803437. [CrossRef]

106. Lee, S.J.; Lodder, B.; Chen, Y.; Patriarchi, T.; Tian, L.; Sabatini, B.L. Cell-type specific asynchronous modulation of PKA by dopamine during reward based learning. bioRxiv 2019, 839035. [CrossRef]

107. Gallo, E.F.; Greenwald, J.; Teboul, E.; Martyniuk, K.M.; Li, Y.; Javitch, J.A.; Balsam, P.D.; Kellendonk, C. Dopamine D2 receptors modulate the cholinergic pause and inhibitory learning. bioRxiv 2020. [CrossRef]

108. Augustine, V.; Ebisu, H.; Zhao, Y.; Lee, S.; Ho, B.; Mizuno, G.O.; Tian, L.; Oka, Y. Temporally and Spatially Distinct Thirst Satiation Signals. Neuron 2019, 103, 242-249. [CrossRef]

109. Alhadeff, A.L.; Goldstein, N.; Park, O.; Klima, M.L.; Vargas, A.; Betley, J.N. Natural and Drug Rewards Engage Distinct Pathways that Converge on Coordinated Hypothalamic and Reward Circuits. Neuron 2019, 103, 891-908. [CrossRef]

110. Corre, J.; van Zessen, R.; Loureiro, M.; Patriarchi, T.; Tian, L.; Pascoli, V.; Lüscher, C. Dopamine neurons projecting to medial shell of the nucleus accumbens drive heroin reinforcement. eLife 2018, 7, e39945. [CrossRef]

111. Liu, Y.; Jean-Richard-dit-Bressel, P.; Yau, J.O.-Y.; Willing, A.; Prasad, A.A.; Power, J.M.; Killcross, S.; Clifford, C.W.G.; McNally, G.P. The mesolimbic dopamine signatures of relapse to alcohol-seeking. bioRxiv 2020. [CrossRef] 
112. de Jong, J.W.; Afjei, S.A.; Pollak Dorocic, I.; Peck, J.R.; Liu, C.; Kim, C.K.; Tian, L.; Deisseroth, K.; Lammel, S. A Neural Circuit Mechanism for Encoding Aversive Stimuli in the Mesolimbic Dopamine System. Neuron 2019, 101, 133-151. [CrossRef] [PubMed]

113. Dong, H.; Wang, J.; Yang, Y.-F.; Shen, Y.; Qu, W.-M.; Huang, Z.-L. Dorsal Striatum Dopamine Levels Fluctuate Across the Sleep-Wake Cycle and Respond to Salient Stimuli in Mice. Front Neurosci. 2019, 13, 242. [CrossRef] [PubMed]

114. Liu, S.; Tian, M.; He, F.; Li, J.; Xie, H.; Liu, W.; Zhang, Y.; Zhang, R.; Yi, M.; Che, F.; et al. Mutations in ASH1L confer susceptibility to Tourette syndrome. Mol. Psychiatry 2020, 25, 476-490. [CrossRef] [PubMed]

115. Robinson, J.E.; Coughlin, G.M.; Hori, A.M.; Cho, J.R.; Mackey, E.D.; Turan, Z.; Patriarchi, T.; Tian, L.; Gradinaru, V. Optical dopamine monitoring with dLight1 reveals mesolimbic phenotypes in a mouse model of neurofibromatosis type 1. eLife 2019, 8, e48983. [CrossRef]

116. Graves, S.M.; Xie, Z.; Stout, K.A.; Zampese, E.; Burbulla, L.F.; Shih, J.C.; Kondapalli, J.; Patriarchi, T.; Tian, L.; Brichta, L.; et al. Dopamine metabolism by a monoamine oxidase mitochondrial shuttle activates the electron transport chain. Nat. Neurosci. 2020, 23, 15-20. [CrossRef]

117. Ziegler, N.; Bätz, J.; Zabel, U.; Lohse, M.J.; Hoffmann, C. FRET-based sensors for the human M1-, M3-, and M5-acetylcholine receptors. Bioorganic Med. Chem. 2011, 19, 1048-1054. [CrossRef]

118. Ravotto, L.; Duffet, L.; Zhou, X.; Weber, B.; Patriarchi, T. A Bright and Colorful Future for G-Protein Coupled Receptor Sensors. Front. Cell. Neurosci. 2020, 14, 67. [CrossRef]

119. Andreoni, A.; Davis, C.M.O.; Tian, L. Measuring brain chemistry using genetically encoded fluorescent sensors. Curr. Opin. Biomed. Eng. 2019, 12, 59-67. [CrossRef]

120. Marvin, J.S.; Scholl, B.; Wilson, D.E.; Podgorski, K.; Kazemipour, A.; Müller, J.A.; Schoch, S.; Quiroz, F.J.U.; Rebola, N.; Bao, H.; et al. Stability, affinity, and chromatic variants of the glutamate sensor iGluSnFR. Nat. Methods 2018, 15, 936-939. [CrossRef]

121. Marvin, J.S.; Shimoda, Y.; Magloire, V.; Leite, M.; Kawashima, T.; Jensen, T.P.; Kolb, I.; Knott, E.L.; Novak, O.; Podgorski, K.; et al. A genetically encoded fluorescent sensor for in vivo imaging of GABA. Nat. Methods 2019, 16, 763-770. [CrossRef]

122. Borden, P.M.; Zhang, P.; Shivange, A.V.; Marvin, J.S.; Cichon, J.; Dan, C.; Podgorski, K.; Figueiredo, A.; Novak, O.; Tanimoto, M.; et al. A fast genetically encoded fluorescent sensor for faithful in vivo acetylcholine detection in mice, fish, worms and flies. bioRxiv 2020. [CrossRef]

123. Mizuno, G.O.; Unger, E.K.; Tian, L. Real time monitoring of neuromodulators in behaving animals using genetically encoded indicators. In Compendium of In Vivo Monitoring in Real-Time Molecular Neuroscience; World Scientific: Singapore, 2019; pp. 1-18, ISBN 9789811206221.

124. Harada, K.; Ito, M.; Wang, X.; Tanaka, M.; Wongso, D.; Konno, A.; Hirai, H.; Hirase, H.; Tsuboi, T.; Kitaguchi, T. Red fluorescent protein-based cAMP indicator applicable to optogenetics and in vivo imaging. Sci. Rep. 2017, 7, 7351. [CrossRef] [PubMed]

125. Kroeze, W.K.; Sassano, M.F.; Huang, X.-P.; Lansu, K.; McCorvy, J.D.; Giguère, P.M.; Sciaky, N.; Roth, B.L. PRESTO-Tango as an open-source resource for interrogation of the druggable human GPCRome. Nat. Struct. Mol. Biol. 2015, 22, 362-369. [CrossRef]

126. Steinmetz, N.A.; Buetfering, C.; Lecoq, J.; Lee, C.R.; Peters, A.J.; Jacobs, E.A.K.; Coen, P.; Ollerenshaw, D.R.; Valley, M.T.; de Vries, S.E.J.; et al. Aberrant Cortical Activity in Multiple GCaMP6-Expressing Transgenic Mouse Lines. eNeuro 2017, 4. [CrossRef]

127. Mosharov, E.V.; Borgkvist, A.; Sulzer, D. Presynaptic effects of L-DOPA and their possible role in dyskinesia. Mov. Disord. 2015, 30, 45-53. [CrossRef]

128. Cragg, S.J.; Rice, M.E. DAncing past the DAT at a DA synapse. Trends Neurosci. 2004, 27, 270-277. [CrossRef] [PubMed]

129. Schultz, W. Multiple Dopamine Functions at Different Time Courses. Annu. Rev. Neurosci. 2007, 30, $259-288$. [CrossRef]

130. Björklund, A.; Hökfelt, T. Handbook of Chemical Neuroanatomy: Classical Transmitters in the CNS; Elsevier: Amsterdam, The Netherlands, 1984; Volume 2.

131. Matsuda, W.; Furuta, T.; Nakamura, K.C.; Hioki, H.; Fujiyama, F.; Arai, R.; Kaneko, T. Single Nigrostriatal Dopaminergic Neurons Form Widely Spread and Highly Dense Axonal Arborizations in the Neostriatum. J. Neurosci. 2009, 29, 444-453. [CrossRef] 
132. Debeir, T.; Ginestet, L.; François, C.; Laurens, S.; Martel, J.-C.; Chopin, P.; Marien, M.; Colpaert, F.; Raisman-Vozari, R. Effect of intrastriatal 6-OHDA lesion on dopaminergic innervation of the rat cortex and globus pallidus. Exp. Neurol. 2005, 193, 444-454. [CrossRef]

133. Moreno, M.; Decara, J.; Pavon, F.J.; Stouffer, D.G.; Edwards, S.; Serrano, A.; Suárez, J.; Parsons, L.H.; de Fonseca, F.R. Cannabinoid dependence induces sustained changes in GABA release in the globus pallidus without affecting dopamine release in the dorsal striatum: A dual microdialysis probe study. Addict. Biol. 2018, 23, 1251-1261. [CrossRef]

134. Gomez-Sintes, R.; Bortolozzi, A.; Artigas, F.; Lucas, J.J. Reduced striatal dopamine DA D2 receptor function in dominant-negative GSK-3 transgenic mice. Eur. Neuropsychopharmacol. 2014, 24, 1524-1533. [CrossRef] [PubMed]

135. Cederfjäll, E.; Sahin, G.; Kirik, D.; Björklund, T. Design of a Single AAV Vector for Coexpression of TH and GCH1 to Establish Continuous DOPA Synthesis in a Rat Model of Parkinson's Disease. Mol. Ther. 2012, 20, 1315-1326. [CrossRef] [PubMed]

136. Pazo, J.H.; Höcht, C.; Barceló, A.C.; Fillipini, B.; Lomastro, M.J. Effect of electrical and chemical stimulation of the subthalamic nucleus on the release of striatal dopamine. Synapse 2010, 64, 905-915. [CrossRef]

137. Li, X.; Li, J.; Gardner, E.L.; Xi, Z.-X. Activation of mGluR7s inhibits cocaine-induced reinstatement of drug-seeking behavior by a nucleus accumbens glutamate-mGluR2/3 mechanism in rats. J. Neurochem. 2010, 114, 1368-1380. [CrossRef]

138. Korkmaz, O.T.; Tunçel, N.; Tunçel, M.; Öncü, E.M.; Şahintürk, V.; Çelik, M. Vasoactive Intestinal Peptide (VIP) Treatment of Parkinsonian Rats Increases Thalamic Gamma-Aminobutyric Acid (GABA) Levels and Alters the Release of Nerve Growth Factor (NGF) by Mast Cells. J. Mol. Neurosci. 2010, 41, 278-287. [CrossRef] [PubMed]

139. Andersson, D.R.; Björnsson, E.; Bergquist, F.; Nissbrandt, H. Motor activity-induced dopamine release in the substantia nigra is regulated by muscarinic receptors. Exp. Neurol. 2010, 221, 251-259. [CrossRef]

140. Andersson, D.R.; Nissbrandt, H.; Bergquist, F. Partial depletion of dopamine in substantia nigra impairs motor performance without altering striatal dopamine neurotransmission. Eur. J. Neurosci. 2006, 24, 617-624. [CrossRef]

141. Yamamura, S.; Ohoyama, K.; Nagase, H.; Okada, M. Zonisamide enhances delta receptor-associated neurotransmitter release in striato-pallidal pathway. Neuropharmacology 2009, 57, 322-331. [CrossRef]

142. Shou, M.; Ferrario, C.R.; Schultz, K.N.; Robinson, T.E.; Kennedy, R.T. Monitoring Dopamine in Vivo by Microdialysis Sampling and On-Line CE-Laser-Induced Fluorescence. Anal. Chem. 2006, 78, 6717-6725. [CrossRef]

143. Schwarz, A.J.; Zocchi, A.; Reese, T.; Gozzi, A.; Garzotti, M.; Varnier, G.; Curcuruto, O.; Sartori, I.; Girlanda, E.; Biscaro, B.; et al. Concurrent pharmacological MRI and in situ microdialysis of cocaine reveal a complex relationship between the central hemodynamic response and local dopamine concentration. NeuroImage 2004, 23, 296-304. [CrossRef]

144. Meissner, W.; Harnack, D.; Hoessle, N.; Bezard, E.; Winter, C.; Morgenstern, R.; Kupsch, A. High frequency stimulation of the entopeduncular nucleus has no effect on striatal dopaminergic transmission. Neurochem. Int. 2004, 44, 281-286. [CrossRef]

145. Lee, C.R.; Abercrombie, E.D.; Tepper, J.M. Pallidal control of substantia nigra dopaminergic neuron firing pattern and its relation to extracellular neostriatal dopamine levels. Neuroscience 2004, 129, 481-489. [CrossRef] [PubMed]

146. Heeringa, M.J.; Abercrombie, E.D. Biochemistry of Somatodendritic Dopamine Release in Substantia Nigra: An In Vivo Comparison with Striatal Dopamine Release. J. Neurochem. 1995, 65, 192-200. [CrossRef]

147. Meissner, W.; Paul, G.; Reum, T.; Reese, R.; Sohr, R.; Morgenstern, R.; Kupsch, A. The influence of pallidal deep brain stimulation on striatal dopaminergic metabolism in the rat. Neurosci. Lett. 2000, 296, 149-152. [CrossRef]

148. Grimm, J.W.; See, R.E. Chronic haloperidol-induced alterations in pallidal GABA and striatal D1-mediated dopamine turnover as measured by dual probe microdialysis in rats. Neuroscience 2000, 100, 507-514. [CrossRef]

149. Balcioglu, A.; Wurtman, R.J. Sibutramine, a serotonin uptake inhibitor, increases dopamine concentrations in rat striatal and hypothalamic extracellular fluid. Neuropharmacology 2000, 39, 2352-2359. [CrossRef] 
150. Opacka-Juffry, J.; Ashworth, S.; Ahier, R.G.; Hume, S.P. Modulatory effects of L-DOPA on D2 dopamine receptors in rat striatum, measured using in vivo microdialysis and PET. J. Neural. Transm. 1998, 105, 349. [CrossRef] [PubMed]

151. Semba, J.; Wakuta, M.S. Regional Differences in the Effects of Glutamate Uptake Inhibitor 1-Trans-Pyrrolidine-2,4-Dicarboxylic Acid on Extracellular Amino Acids and Dopamine in Rat Brain: An In Vivo Microdialysis Study. Gen. Pharmacol. Vasc. Syst. 1998, 31, 399-404. [CrossRef]

152. Grimm, J.W.; See, R.E. Unique activation of extracellular striato-pallidal neurotransmitters in rats following acute risperidone. Brain Res. 1998, 801, 182-189. [CrossRef]

153. Ferraro, L.; O'Connor, W.T.; Antonelli, T.; Fuxe, K.; Tanganelli, S. Differential Effects of lntrastriatal Neurotensin (1-13) and Neurotensin (8-13) on Striatal Dopamine and Pallidal GABA Release. A Dual-probe Microdialysis Study in the Awake Rat. Eur. J. Neurosci. 1997, 9, 1838-1846. [CrossRef]

154. Rimondini, R.; O'Connor, W.T.; Sillard, R.; Mutt, V.; Ungerstedt, U.; Fuxe, K. The secretory trypsin inhibitor like-peptide, PEC-60 increases dopamine D2 receptor agonist induced inhibition of GABA release in the dorsolateral neostriatum of the awake freely moving rat. An in vivo microdialysis study. Regul. Pept. 1996, 61, 111-117. [CrossRef]

155. Rimondini, R.; O'Connor, W.T.; Ferré, S.; Sillard, R.; Agerberth, B.; Mutt, V.; Ungerstedt, U.; Fuxe, K. PEC-60 increases dopamine but not GABA release in the dorsolateral neostriatum of the halothane anaesthetized rat. An in vivo microdialysis study. Neurosci. Lett. 1994, 177, 53-57. [CrossRef]

156. Ferré, S. Antagonistic interaction between adenosine A2A receptors and dopamine D2 receptors in the ventral striopallidal system. Implications for the treatment of schizophrenia. Neuroscience 1994, 63, 765-773. [CrossRef]

157. Drew, K.L.; O'Connor, W.T.; Kehr, J.; Ungerstedt, U. Regional specific effects of clozapine and haloperidol on GABA and dopamine release in rat basal ganglia. Eur. J. Pharmacol. 1990, 187, 385-397. [CrossRef]

158. Drew, K.L.; O'Connor, W.T.; Kehr, J.; Ungerstedt, U. Characterization of gamma-aminobutyric acid and dopamine overflow following acute implantation of a microdialysis probe. Life Sci. 1989, 45, 1307-1317. [CrossRef]

159. Di Chiara, G.; Imperato, A. Drugs abused by humans preferentially increase synaptic dopamine concentrations in the mesolimbic system of freely moving rats. Proc. Natl. Acad. Sci. USA 1988, 85, 5274-5278. [CrossRef]

160. Wydra, K.; Golembiowska, K.; Zaniewska, M.; Kamińska, K.; Ferraro, L.; Fuxe, K.; Filip, M. Accumbal and pallidal dopamine, glutamate and GABA overflow during cocaine self-administration and its extinction in rats. Addict. Biol. 2013, 18, 307-324. [CrossRef] [PubMed]

161. Borgkvist, A.; Malmlöf, T.; Feltmann, K.; Lindskog, M.; Schilström, B. Dopamine in the hippocampus is cleared by the norepinephrine transporter. Int. J. Neuropsychopharmacol. 2012, 15, 531-540. [CrossRef]

162. Sotomayor-Zárate, R.; Araya, K.A.; Pereira, P.; Blanco, E.; Quiroz, G.; Pozo, S.; Carreño, P.; Andrés, M.E.; Forray, M.I.; Gysling, K. Activation of GABA-B receptors induced by systemic amphetamine abolishes dopamine release in the rat lateral septum. J. Neurochem. 2010, 114, 1678-1686. [CrossRef]

163. Smith, D.G.; Tzavara, E.T.; Shaw, J.; Luecke, S.; Wade, M.; Davis, R.; Salhoff, C.; Nomikos, G.G.; Gehlert, D.R. Mesolimbic Dopamine Super-Sensitivity in Melanin-Concentrating Hormone-1 Receptor-Deficient Mice. J. Neurosci. 2005, 25, 914-922. [CrossRef]

164. Anagnostakis, Y.; Kastellakis, A.; Spyraki, C. Dizocilpine (MK-801) and tetrodotoxin influence accumbal dopamine release evoked by intrapallidal morphine. Eur. Neuropsychopharmacol. 1998, 8, 47-53. [CrossRef]

165. Ferre, S.; Cortes, R.; Artigas, F. Dopaminergic regulation of the serotonergic raphe-striatal pathway: Microdialysis studies in freely moving rats. J. Neurosci. 1994, 14, 4839-4846. [CrossRef]

166. Klitenick, M.A.; Kalivas, P.W. Behavioral and neurochemical studies of opioid effects in the pedunculopontine nucleus and mediodorsal thalamus. J Pharmacol. Exp. Ther. 1994, 269, 437-448. [PubMed]

167. Parsons, L.H.; Justice, J.B. Serotonin and Dopamine Sensitization in the Nucleus Accumbens, Ventral Tegmental Area, and Dorsal Raphe Nucleus Following Repeated Cocaine Administration. J. Neurochem. 1993, 61, 1611-1619. [CrossRef]

168. Hurd, Y.L.; McGrego, A.; Pontén, M. In vivo Amygdala Dopamine Levels Modulate Cocaine Self-administration Behaviour in the Rat: D1 Dopamine Receptor Involvement. Eur. J. Neurosci. 1997, 9 , 2541-2548. [CrossRef] 
169. Hurd, Y.L.; Pontén, M. Cocaine self-administration behavior can be reduced or potentiated by the addition of specific dopamine concentrations in the nucleus accumbens and amygdala using in vivo microdialysis. Behav. Brain Res. 2000, 116, 177-186. [CrossRef]

170. Reid, M.S.; Herrera-Marschitz, M.; Ungerstedt, U. Effects of Intranigral Substance P and Neurokinin A Injections on Extracellular Dopamine Levels Measured with Microdialysis in the Striatum and Frontoparietal Cortex of Rats. J. Neurochem. 1991, 57, 970-974. [CrossRef] [PubMed]

171. Herrera-Marschitz, M.; Goiny, M.; Utsumi, H.; Ungerstedt, U. Mesencephalic dopamine innervation of the frontoparietal (sensorimotor) cortex of the rat: A microdialysis study. Neurosci. Lett. 1989, 97, 266-270. [CrossRef]

172. Kretschmer, B.D.; Goiny, M.; Herrera-Marschitz, M. Effect of Intracerebral Administration of NMDA and AMPA on Dopamine and Glutamate Release in the Ventral Pallidum and on Motor Behavior. J. Neurochem. 2000, 74, 2049-2057. [CrossRef] [PubMed]

173. Sizemore, G.M.; Co, C.; Smith, J.E. Ventral pallidal extracellular fluid levels of dopamine, serotonin, gamma amino butyric acid, and glutamate during cocaine self-administration in rats. Psychopharmacology 2000, 150, 391-398. [CrossRef]

174. Fuchs, H.; Hauber, W. Reverse microdialysis of ionotropic glutamate receptor agonists in the rat globus pallidus increased extracellular dopamine. Neurosci. Lett. 2003, 343, 37-40. [CrossRef]

175. Fuchs, H.; Hauber, W. Changes in extracellular dopamine in the rat globus pallidus induced by typical and atypical antipsychotic drugs. Neurochem. Int. 2004, 45, 1029-1038. [CrossRef]

176. Fuchs, H.; Nagel, J.; Hauber, W. Effects of physiological and pharmacological stimuli on dopamine release in the rat globus pallidus. Neurochem. Int. 2005, 47, 474-481. [CrossRef] [PubMed]

177. Grasshoff, C.; Herrera-Marschitz, M.; Goiny, M.; Kretschmer, B.D. Modulation of ventral pallidal dopamine and glutamate release by the intravenous anesthetic propofol studied by in vivo microdialysis. Amino Acids 2005, 28, 145-148. [CrossRef] [PubMed]

178. Melendez, R.I.; Rodd, Z.A.; McBride, W.J.; Murphy, J.M. Dopamine receptor regulation of ethanol intake and extracellular dopamine levels in the ventral pallidum of alcohol preferring (P) rats. Drug Alcohol Depend. 2005, 77, 293-301. [CrossRef]

179. Cauli, O.; Mlili, N.; Rodrigo, R.; Felipo, V. Hyperammonaemia alters the mechanisms by which metabotropic glutamate receptors in nucleus accumbens modulate motor function. J. Neurochem. 2007, 103, 38-46. [CrossRef] [PubMed]

180. Ding, Z.-M.; Oster, S.M.; Hall, S.R.; Engleman, E.A.; Hauser, S.R.; McBride, W.J.; Rodd, Z.A. The stimulating effects of ethanol on ventral tegmental area dopamine neurons projecting to the ventral pallidum and medial prefrontal cortex in female Wistar rats: Regional difference and involvement of serotonin-3 receptors. Psychopharmacology 2011, 216, 245-255. [CrossRef] [PubMed]

181. Orosco, M.; Rough, C.; Meile, M.J.; Nicolaidis, S. Spontaneous feeding-related monoamine changes in rostromedial hypothalamus of the obese Zucker rat: A microdialysis study. Physiol. Behav. 1995, 57, 1103-1106. [CrossRef]

182. Timmerman, W.; Poelman, R.T.; Westerink, B.H.C.; Schuiling, G.A. Semicircadian Rhythm of Dopamine Release in the Mediobasal Hypothalamus in Awake Rats during Pseudopregnancy: Evidence that a Thyrotropin-Releasing Hormone Analogue Stimulates Dopamine Release and thereby Inhibits Prolactin Secretion. NEN 1995, 62, 434-443. [CrossRef]

183. Fetissov, S.O.; Meguid, M.M.; Chen, C.; Miyata, G. Synchronized release of dopamine and serotonin in the medial and lateral hypothalamus of rats. Neuroscience 2000, 101, 657-663. [CrossRef]

184. Flik, G.; Folgering, J.H.A.; Cremers, T.I.H.F.; Westerink, B.H.C.; Dremencov, E. Interaction Between Brain Histamine and Serotonin, Norepinephrine, and Dopamine Systems: In Vivo Microdialysis and Electrophysiology Study. J. Mol. Neurosci. 2015, 56, 320-328. [CrossRef] [PubMed]

185. Ortega, J.E.; Katner, J.; Davis, R.; Wade, M.; Nisenbaum, L.; Nomikos, G.G.; Svensson, K.A.; Perry, K.W. Modulation of neurotransmitter release in orexin/hypocretin-2 receptor knockout mice: A microdialysis study. J. Neurosci. Res. 2012, 90, 588-596. [CrossRef] [PubMed]

186. Nisijima, K.; Kuboshima, K.; Shioda, K.; Yoshino, T.; Iwamura, T.; Kato, S. Memantine attenuates 3,4-methylenedioxymethamphetamine-induced hyperthermia in rats. Neurosci. Lett. 2012, 531, 198-203. [CrossRef] 
187. Swanson, C.J.; Perry, K.W.; Koch-Krueger, S.; Katner, J.; Svensson, K.A.; Bymaster, F.P. Effect of the attention deficit/hyperactivity disorder drug atomoxetine on extracellular concentrations of norepinephrine and dopamine in several brain regions of the rat. Neuropharmacology 2006, 50, 755-760. [CrossRef] [PubMed]

188. Melis, M.R.; Succu, S.; Mascia, M.S.; Cortis, L.; Argiolas, A. Extra-cellular dopamine increases in the paraventricular nucleus of male rats during sexual activity. Eur. J. Neurosci. 2003, 17, 1266-1272. [CrossRef]

189. Gören, M.Z.; Aker, R.; Yananlı, H.R.; Onat, F.Y. Extracellular Concentrations of Catecholamines and Amino Acids in the Dorsomedial Hypothalamus of Kindled Rats. Pharmacology 2003, 68, 190-197. [CrossRef]

190. Obi, K.; Amano, I.; Takatsuru, Y. Role of dopamine on functional recovery in the contralateral hemisphere after focal stroke in the somatosensory cortex. Brain Res. 2018, 1678, 146-152. [CrossRef]

191. Caruana, D.A.; Sorge, R.E.; Stewart, J.; Chapman, C.A. Dopamine Has Bidirectional Effects on Synaptic Responses to Cortical Inputs in Layer II of the Lateral Entorhinal Cortex. J. Neurophysiology 2006, 96, 3006-3015. [CrossRef]

192. Pum, M.E.; Huston, J.P.; De Souza Silva, M.A.; Müller, C.P. Visual sensory-motor gating by serotonin activation in the medial prefrontal and occipital, but not in the rhinal, cortices in rats. Neuroscience 2008, 153, 361-372. [CrossRef]

193. Devoto, P.; Flore, G.; Pani, L.; Gessa, G.L. Evidence for co-release of noradrenaline and dopamine from noradrenergic neurons in the cerebral cortex. Mol. Psychiatry 2001, 6, 657-664. [CrossRef]

194. Müller, C.P.; Huston, J.P. Dopamine activity in the occipital and temporal cortices of rats: Dissociating effects of sensory but not pharmacological stimulation. Synapse 2007, 61, 254-258. [CrossRef] [PubMed]

195. Ash, E.S.; Heal, D.J.; Stanford, S.C. Contrasting changes in extracellular dopamine and glutamate along the rostrocaudal axis of the anterior cingulate cortex of the rat following an acute d-amphetamine or dopamine challenge. Neuropharmacology 2014, 87, 180-187. [CrossRef]

196. Mabrouk, O.S.; Semaan, D.Z.; Mikelman, S.; Gnegy, M.E.; Kennedy, R.T. Amphetamine stimulates movement through thalamocortical glutamate release. J. Neurochem. 2014, 128, 152-161. [CrossRef] [PubMed]

197. Chung, Y.-C.; Li, Z.; Dai, J.; Meltzer, H.Y.; Ichikawa, J. Clozapine increases both acetylcholine and dopamine release in rat ventral hippocampus: Role of 5-HT1A receptor agonism. Brain Res. 2004, 1023, 54-63. [CrossRef]

198. Muraoka, H.; Oshibuchi, H.; Kawano, M.; Kawano, T.; Tsutsumi, T.; Yamada, M.; Ishigooka, J.; Nishimura, K.; Inada, K. Escitalopram attenuates fear stress-induced increase in amygdalar dopamine following methamphetamine-induced sensitisation: Implications of fine-tuning action of selective serotonin reuptake inhibitors on emotional processing. Eur. J. Pharmacol. 2018, 834, 1-9. [CrossRef]

199. Kawano, T.; Oshibuchi, H.; Kawano, M.; Muraoka, H.; Tsutsumi, T.; Yamada, M.; Ishigooka, J.; Nishimura, K.; Inada, K. Diazepam suppresses the stress-induced dopaminergic release in the amygdala of methamphetamine-sensitized rat. Eur. J. Pharmacol. 2018, 833, 247-254. [CrossRef]

200. Del Arco, A.; Ronzoni, G.; Mora, F. Hypofunction of prefrontal cortex NMDA receptors does not change stress-induced release of dopamine and noradrenaline in amygdala but disrupts aversive memory. Psychopharmacology 2015, 232, 2577-2586. [CrossRef] [PubMed]

201. Izumo, N.; Ishibashi, Y.; Ohba, M.; Morikawa, T.; Manabe, T. Decreased voluntary activity and amygdala levels of serotonin and dopamine in ovariectomized rats. Behav. Brain Res. 2012, 227, 1-6. [CrossRef]

202. Oshibuchi, H.; Inada, K.; Sugawara, H.; Ishigooka, J. Aripiprazole and haloperidol suppress excessive dopamine release in the amygdala in response to conditioned fear stress, but show contrasting effects on basal dopamine release in methamphetamine-sensitized rats. Eur. J. Pharmacol. 2009, 615, 83-90. [CrossRef]

203. Barr, G.A.; Moriceau, S.; Shionoya, K.; Muzny, K.; Gao, P.; Wang, S.; Sullivan, R.M. Transitions in infant learning are modulated by dopamine in the amygdala. Nat. Neurosci. 2009, 12, 1367-1369. [CrossRef]

204. Tor-Agbidye, J.; Yamamoto, B.; Bowyer, J.F. Seizure Activity and Hyperthermia Potentiate the Increases in Dopamine and Serotonin Extracellular Levels in the Amygdala during Exposure to d-Amphetamine. Toxicol. Sci. 2001, 60, 103-111. [CrossRef] [PubMed]

205. Sotomayor-Zárate, R.; Renard, G.M.; Araya, K.A.; Carreño, P.; Fuentealba, J.A.; Andrés, M.E.; Gysling, K. Long-term loss of dopamine release mediated by CRF-1 receptors in the rat lateral septum after repeated cocaine administration. Behav. Brain Res. 2013, 250, 206-210. [CrossRef] [PubMed]

206. Chefer, V.I.; Denoroy, L.; Zapata, A.; Shippenberg, T.S. Mu opioid receptor modulation of somatodendritic dopamine overflow: GABAergic and glutamatergic mechanisms. Eur. J. Neurosci. 2009, 30, 272-278. [CrossRef] [PubMed] 
207. Cobb, W.S.; Abercrombie, E.D. Relative involvement of globus pallidus and subthalamic nucleus in the regulation of somatodendritic dopamine release in substantia nigra is dopamine-dependent. Neuroscience 2003, 119, 777-786. [CrossRef]

208. Yamamuro, Y.; Hori, K.; Tanaka, J.; Iwano, H.; Nomura, M. Septo-hippocampal cholinergic system under the discrimination learning task in the rat: A microdialysis study with the dual-probe approach. Brain Res. 1995, 684, 1-7. [CrossRef]

209. Miyazaki, K.W.; Miyazaki, K.; Doya, K. Activation of the central serotonergic system in response to delayed but not omitted rewards. Eur. J. Neurosci. 2011, 33, 153-160. [CrossRef]

210. Neugebauer, F.; Korz, V.; Frey, J.U. Modulation of extracellular monoamine transmitter concentrations in the hippocampus after weak and strong tetanization of the perforant path in freely moving rats. Brain Res. 2009, 1273, 29-38. [CrossRef]

211. Smolders, I.; Clinckers, R.; Meurs, A.; De Bundel, D.; Portelli, J.; Ebinger, G.; Michotte, Y. Direct enhancement of hippocampal dopamine or serotonin levels as a pharmacodynamic measure of combined antidepressant-anticonvulsant action. Neuropharmacology 2008, 54, 1017-1028. [CrossRef]

212. Venton, B.J.; Zhang, H.; Garris, P.A.; Phillips, P.E.M.; Sulzer, D.; Wightman, R.M. Real-time decoding of dopamine concentration changes in the caudate-putamen during tonic and phasic firing. J. Neurochem. 2003, 87, 1284-1295. [CrossRef]

213. Paxinos, G.; Watson, C. The Rat Brain in Stereotaxic Coordinates: Hard Cover Edition, 6th ed.; Elsevier: Amsterdam, The Netherlands, 2006.

214. Davies, M.I.; Cooper, J.D.; Desmond, S.S.; Lunte, C.E.; Lunte, S.M. Analytical considerations for microdialysis sampling. Adv. Drug Deliv. Rev. 2000, 45, 169-188. [CrossRef]

215. Robinson, D.L.; Heien, M.L.A.V.; Wightman, R.M. Frequency of Dopamine Concentration Transients Increases in Dorsal and Ventral Striatum of Male Rats during Introduction of Conspecifics. J. Neurosci. 2002, 22, 10477-10486. [CrossRef] [PubMed]

216. Hamid, A.A.; Pettibone, J.R.; Mabrouk, O.S.; Hetrick, V.L.; Schmidt, R.; Vander Weele, C.M.; Kennedy, R.T.; Aragona, B.J.; Berke, J.D. Mesolimbic dopamine signals the value of work. Nat. Neurosci. 2016, 19, 117-126. [CrossRef] [PubMed]

217. Roitman, M.F. Dopamine Operates as a Subsecond Modulator of Food Seeking. J. Neurosci. 2004, 24, 1265-1271. [CrossRef] [PubMed]

218. Phillips, P.E.M.; Stuber, G.D.; Heien, M.L.A.V.; Wightman, R.M.; Carelli, R.M. Subsecond dopamine release promotes cocaine seeking. Nature 2003, 422, 614-618. [CrossRef] [PubMed]

219. Howe, M.W.; Tierney, P.L.; Sandberg, S.G.; Phillips, P.E.M.; Graybiel, A.M. Prolonged dopamine signalling in striatum signals proximity and value of distant rewards. Nature 2013, 500, 575-579. [CrossRef] [PubMed]

220. Wightman, R.M.; Heien, M.L.A.V.; Wassum, K.M.; Sombers, L.A.; Aragona, B.J.; Khan, A.S.; Ariansen, J.L.; Cheer, J.F.; Phillips, P.E.M.; Carelli, R.M. Dopamine release is heterogeneous within microenvironments of the rat nucleus accumbens. Eur. J. Neurosci. 2007, 26, 2046-2054. [CrossRef] [PubMed]

221. Oleson, E.B.; Salek, J.; Bonin, K.D.; Jones, S.R.; Budygin, E.A. Real-time voltammetric detection of cocaine-induced dopamine changes in the striatum of freely moving mice. Neurosci. Lett. 2009, 467, 144-146. [CrossRef]

222. Bass, C.E.; Grinevich, V.P.; Vance, Z.B.; Sullivan, R.P.; Bonin, K.D.; Budygin, E.A. Optogenetic control of striatal dopamine release in rats. J. Neurochem. 2010, 114, 1344-1352. [CrossRef] [PubMed]

223. Vickrey, T.L.; Condron, B.; Venton, B.J. Rapid Detection of Endogenous Dopamine Changes in Drosophila melanogaster using Fast-Scan Cyclic Voltammetry. Anal. Chem. 2009, 81, 9306-9313. [CrossRef]

224. Pisano, F.; Pisanello, M.; Lee, S.J.; Lee, J.; Maglie, E.; Balena, A.; Sileo, L.; Spagnolo, B.; Bianco, M.; Hyun, M.; et al. Depth-resolved fiber photometry with a single tapered optical fiber implant. Nat. Methods 2019, 16, 1185-1192. [CrossRef] [PubMed]

225. Kesner, A.J.; Shin, R.; Calva, C.B.; Don, R.F.; Junn, S.; Potter, C.T.; Ramsey, L.A.; Abou-Elnaga, A.F.; Cover, C.G.; Wang, D.V.; et al. Supramammillary neurons projecting to the septum regulate dopamine and motivation for environmental interaction. bioRxiv 2020. [CrossRef]

226. Lefevre, E.M.; Pisansky, M.T.; Toddes, C.; Baruffaldi, F.; Pravetoni, M.; Tian, L.; Kono, T.J.Y.; Rothwell, P.E. Interruption of continuous opioid exposure exacerbates drug-evoked adaptations in the mesolimbic dopamine system. Neuropsychopharmacology 2020, 45, 1781-1792. [CrossRef] [PubMed] 
227. Kramer, P.F.; Twedell, E.L.; Shin, J.H.; Zhang, R.; Khaliq, Z.M. Axonal mechanisms mediating GABA-A receptor inhibition of striatal dopamine release. bioRxiv 2020. [CrossRef]

228. Tang, W.; Kochubey, O.; Kintscher, M.; Schneggenburger, R. Dopamine in the basal amygdala signals salient somatosensory events during fear learning. bioRxiv 2019, 716589. [CrossRef]

229. Eisenhofer, G.; Kopin, I.J.; Goldstein, D.S. Catecholamine Metabolism: A Contemporary View with Implications for Physiology and Medicine. Pharmacol. Rev. 2004, 56, 331-349. [CrossRef] [PubMed]

230. Berridge, C.W.; Waterhouse, B.D. The locus coeruleus-noradrenergic system: Modulation of behavioral state and state-dependent cognitive processes. Brain Res. Revs. 2003, 42, 33-84. [CrossRef]

231. Léna, I.; Parrot, S.; Deschaux, O.; Muffat-Joly, S.; Sauvinet, V.; Renaud, B.; Suaud-Chagny, M.-F.; Gottesmann, C. Variations in extracellular levels of dopamine, noradrenaline, glutamate, and aspartate across the sleep-wake cycle in the medial prefrontal cortex and nucleus accumbens of freely moving rats. J. Neurosci. Res. 2005, 81, 891-899. [CrossRef]

232. Ihalainen, J.A.; Riekkinen Jr, P.; Feenstra, M.G.P. Comparison of dopamine and noradrenaline release in mouse prefrontal cortex, striatum and hippocampus using microdialysis. Neurosci. Lett. 1999, 277, 71-74. [CrossRef]

233. Finlay, J.M.; Zigmond, M.J.; Abercrombie, E.D. Increased dopamine and norepinephrine release in medial prefrontal cortex induced by acute and chronic stress: Effects of diazepam. Neuroscience 1995, 64, 619-628. [CrossRef]

234. Li, X.-M.; Perry, K.W.; Wong, D.T.; Bymaster, F.P. Olanzapine increases in vivo dopamine and norepinephrine release in rat prefrontal cortex, nucleus accumbens and striatum. Psychopharmacology 1998, 136, 153-161. [CrossRef]

235. Sabatini, B.L. The impact of reporter kinetics on the interpretation of data gathered with fluorescent reporters. bioRxiv 2019, 834895. [CrossRef]

236. Paoletti, P.; Ellis-Davies, G.C.R.; Mourot, A. Optical control of neuronal ion channels and receptors. Nat. Rev. Neurosci. 2019, 20, 514-532. [CrossRef] [PubMed]

237. Horton, N.G.; Wang, K.; Kobat, D.; Clark, C.G.; Wise, F.W.; Schaffer, C.B.; Xu, C. In vivo three-photon microscopy of subcortical structures within an intact mouse brain. Nat. Photonics 2013, 7, 205-209. [CrossRef] [PubMed]

238. Gomez, J.L.; Bonaventura, J.; Lesniak, W.; Mathews, W.B.; Sysa-Shah, P.; Rodriguez, L.A.; Ellis, R.J.; Richie, C.T.; Harvey, B.K.; Dannals, R.F.; et al. Chemogenetics revealed: DREADD occupancy and activation via converted clozapine. Science 2017, 357, 503-507. [CrossRef] [PubMed]

239. Nagai, Y.; Miyakawa, N.; Takuwa, H.; Hori, Y.; Oyama, K.; Ji, B.; Takahashi, M.; Huang, X.-P.; Slocum, S.T.; DiBerto, J.F.; et al. Deschloroclozapine, a potent and selective chemogenetic actuator enables rapid neuronal and behavioral modulations in mice and monkeys. Nat. Neurosci. 2020,1-11. [CrossRef]

240. Frohlich, J.; Van Horn, J.D. Reviewing the ketamine model for schizophrenia. J. Psychopharmacol. 2014, 28, 287-302. [CrossRef]

241. Martianova, E.; Aronson, S.; Proulx, C.D. Multi-Fiber Photometry to Record Neural Activity in Freely-Moving Animals. JoVE 2019, 60278. [CrossRef]

242. Bruno, C.A.; O’Brien, C.; Bryant, S.; Mejaes, J.; Pizzano, C.; Estrin, D.J.; Barker, D.J. pMAT: An Open-Source, Modular Software Suite for the Analysis of Fiber Photometry Calcium Imaging. bioRxiv 2020. [CrossRef]

Publisher's Note: MDPI stays neutral with regard to jurisdictional claims in published maps and institutional affiliations.

(C) 2020 by the authors. Licensee MDPI, Basel, Switzerland. This article is an open access article distributed under the terms and conditions of the Creative Commons Attribution (CC BY) license (http://creativecommons.org/licenses/by/4.0/). 